\title{
EL CONVENIO DE ALBUFEIRA: UN ANÁLISIS CON MOTIVO DEL VIGÉSIMO ANIVERSARIO DE SU ADOPCIÓN ${ }^{1}$
}

\section{THE ALBUFEIRA CONVENTION: AN ANALYSIS ON THE OCCASION OF THE $20^{\text {TH }}$ ANNIVERSARY OF ITS ADOPTION}

\author{
IgNACIO ÁlvAREZ ARCA \\ Universidad de Málaga \\ nalvarez@uma.es
}

Fecha de recepción: 4 de abril de 2019 / Fecha de aceptación: 17 de octubre de 2019

RESUMEN: En el año 1998 España y Portugal adoptaron el Convenio de Albufeira para gestionar los recursos hídricos compartidos entre ambos Estados. Por primera vez, la protección medioambiental y la gestión sostenible de los recursos hídricos y los ecosistemas dependientes pasó a ser el objetivo fundamental de las relaciones convencionales. Estas relaciones se han desarrollado a lo largo de más de cien años, aunque con unos objetivos muy diferentes. Ahora que se ha cumplido el vigésimo aniversario de su adopción es una buena ocasión para analizar el Convenio, sus deficiencias del pasado y los retos del futuro. El Convenio de Albufeira goza de plena vigencia y puede garantizar la protección y sostenibilidad de los recursos hídricos compartidos por otros veinte años. Sin embargo, la revisión que se llevará a cabo de la Directiva Marco del Agua en el presente año y la adopción de la Agenda 2030 ofrecen el contexto adecuado para que España y Portugal vayan más allá en sus relaciones y perfeccionen el contenido del Convenio para hacer frente a la amenaza de la escasez y las sequías, en aumento como consecuencia del cambio climático.

ABSTRACT: In 1998 Spain and Portugal adopted the Albufeira Convention to manage shared water resources between both States. For the first time,

\footnotetext{
${ }^{1}$ Esta investigación se enmarca dentro del programa de ayudas FPU/2017 del Ministerio de Educación, Cultura y Deporte del Gobierno de España y del proyecto de investigación "Los muros y el derecho internacional contemporáneo: implicaciones para la seguridad, la dignidad de la persona y el desarrollo sostenible (DER2015-65486-R)", del Ministerio de Economía, Industria y Competitividad del Gobierno de España.
} 
environmental protection and sustainable management of water resources and dependent ecosystems became the main goal of the conventional relationships. Those relationships have been developed over more than hundred years, even though with other different goals. Now, in the twentieth anniversary of its adoption, it is a good moment to analyse the Convention, its past deficiencies and its future challenges. The Albufeira Convention is fully enforceable and can guarantee the protection and sustainability of the shared water resources for a further twenty years. However, the updating of the Water Framework Directive, that will take place this year, and the adoption of the Agenda 2030 provide the suitable context to deepen relationships and improve the Convention to face the threat of scarcity and drought, which are increasing due to climate change.

RESUM: L'any 1998 Espanya i Portugal van adoptar el Conveni d'Albufeira per gestionar els recursos hídrics compartits entre tots dos estats. Per primera vegada, la protecció mediambiental i la gestió sostenible dels recursos hídrics i els ecosistemes que en depenen va passar a ser l'objectiu fonamental de les relacions convencionals. Aquestes relacions s'han desenvolupat al llarg de més de cent anys, encara que amb uns objectius molt diferents. Ara que fa vint anys que es va adoptar el conveni, és una bona ocasió per analitzar-ne les deficiències del passat i els reptes del futur. El Conveni d'Albufeira gaudeix de plena vigència i pot garantir la protecció i sostenibilitat dels recursos hídrics compartits per vint anys més. No obstant això, la revisió que enguany es durà a terme de la Directiva marc de l'aigua i l'adopció de l'Agenda 2030 ofereixen el context adequat perquè Espanya i Portugal vagin més enllà en les seves relacions i perfeccionin el contingut del conveni per fer front a l'amenaça de l'escassetat i les sequeres, en augment com a conseqüència del canvi climàtic.

PALABRAS CLAVE: Recursos hídricos compartidos - Cuenca hidrográfica internacional - Convenio de Albufeira - Sostenibilidad - Relaciones transfronterizas - España y Portugal.

KEYWORDS: Shared water resources - International river basin - Albufeira Convention - Sustainability - Cross-border relations - Spain and Portugal. 
PARAULES CLAU: Recursos hídrics compartits - Conca hidrogràfica internacional - Conveni d'Albufeira — sostenibilita — relacions transfrontereres - Espanya i Portugal.

SUMARIO: I. Introducción. II. Antecedentes. 1. Los acuerdos Bilaterales entre España y Portugal. 2. El contexto internacional III. El Convenio de Albufeira. 1. El Convenio: naturaleza y estructura. 2. El marco institucional del Convenio de Albufeira. 3. El contenido sustantivo del Convenio de Albufeira. IV. Las deficiencias del pasado y los retos del futuro del Convenio de Albufeira. 1. Los incumplimientos de España. 2. La política hídrica de España: el trasvase TajoSegura. 3. Las posibles reformas del Convenio. V. Conclusiones. VI. Bibliografía.

\section{INTRODUCCIÓN}

El agua es un recurso natural indispensable para la existencia y desarrollo de la vida sin la cual ninguna de las formas y seres de la naturaleza podría subsistir. Más allá de su naturaleza y su función de fuente de vida, los recursos hídricos están destinados a numerosos usos que van desde la satisfacción de las necesidades humanas primarias hasta la navegación y otros usos distintos de la navegación como los usos agrícolas, los relacionados con la economía y los usos comerciales e industriales, así como los usos vinculados al ocio. De ahí que autores como ARIAS MALDONADO lo consideren como un capital natural crítico, entendido tal como: "aquella entidad o componente natural cuya pérdida comprometerá la supervivencia 0 el bienestar humanos y no podrá reemplazarse"2.

A través Derecho Internacional del Medio Ambiente (DIMA, en adelante) se ha desarrollado un marco jurídico de referencia para garantizar la protección los recursos hídricos compartidos. Una protección que no se circunscribe únicamente al buen estado cuantitativo de las aguas, sino también al cualitativo. Ampliando el enfoque y el objeto de protección se garantiza la protección de los ecosistemas dependientes de los recursos hídricos. Del mismo modo, este régimen jurídico tiene como objetivo sobreponerse a la gran variabilidad por la que se caracteriza la disponibilidad de los recursos hídricos ${ }^{3}$ en el contexto del

\footnotetext{
${ }^{2}$ Manuel Arias Maldonado, Antropoceno. La política en la era de la humana, Taurus, 2018, p. 82. El mismo autor define "capital natural" en la p.81 del siguiente modo: "El capital natural está compuesto por la suma de todos los recursos naturales que los humanos emplean para fines humanos y es ese uso el que convierte a la naturaleza en un recurso, aunque las funciones puedan cumplirse sin que el mundo natural sea tocado por el ser humano".

${ }^{3}$ La variabilidad en la disponibilidad de los recursos hídricos ha sido puesta de relieve en: OCDE, Principios de Gobernanza del Agua de la OCDE, 2015, p.1. Disponible en internet en:
} 
cambio climático, donde los problemas derivados de la escasez y la sequía ${ }^{4}$ son cada vez más frecuentes. Gran parte de los recursos hídricos se destinan a la producción agrícola ${ }^{5}$, esencial para garantizar la alimentación de la población. Teniendo en cuenta que la población mundial está aumentando en 80 millones de personas cada año, y que se espera que en 2100 existan más de 11.184 millones de habitantes ${ }^{6}$, dicha producción deberá incrementarse necesariamente para satisfacer las necesidades alimenticias, lo que supone un reto para el conjunto de los Estados.

La península ibérica no es ajena a las amenazas climáticas y de gestión planteadas, lo que hace de la cooperación bilateral entre España y Portugal una herramienta imprescindible para garantizar la disponibilidad de los recursos hídricos en el largo plazo. Son cinco las cuencas hidrográficas internacionales que comparten ambos Estados: la de los ríos Miño, Limia, Duero, Tajo y Guadiana. Partiendo de este marco general, resulta de sumo interés analizar la cooperación institucionalizada establecida en el Convenio de Albufeira. En 2018 se cumplió el vigésimo aniversario de la adopción de dicho tratado que, por primera vez, y pese a que España y Portugal ya habían concluido tratados desde el siglo XIX en lo referente a la gestión de los recursos hídricos compartidos, tiene como uno de sus objetivos principales garantizar su sostenibilidad, así como la protección de los ecosistemas marinos y terrestres dependientes.

En el presente trabajo se exponen de manera somera los antecedentes del Convenio de Albufeira. Tras esta primera parte, se analizará el contenido del Convenio de Albufeira para poder establecer una imagen sobre su contenido sustantivo y la estructura institucional. Posteriormente, y aprovechando la oportunidad que el vigésimo aniversario de su adopción ofrece, se estudiará el grado de cumplimiento de las obligaciones en él contenidas y se estudiarán

\footnotetext{
<https://www.oecd.org/cfe/regional-policy/OECD-Principles-Water-spanish.pdf> consulta: 11/06/2019]

${ }^{4}$ La escasez se produce por una gestión ineficiente de los recursos hídricos, que somete a los mismos a un alto grado de estrés. Sin embargo, la sequía es consecuencia del aumento progresivo de las temperaturas $y$, por consiguiente, del cambio climático.

${ }^{5}$ Los usos a los que se destinan esta cantidad de agua se distribuyen del siguiente modo: el $69 \%$ de las extracciones se destinan a usos agrícolas, el 19\% a usos industriales y el $12 \%$ restante al consumo doméstico. UNESCO, Informe Mundial de las Naciones Unidas sobre el Desarrollo de los Recursos Hídricos 2019. No dejar a nadie atrás, 2019, p. 27. Disponible en internet en: <https://unesdoc.unesco.org/ark:/48223/pf0000367304> [Última consulta: 11/06/2019].

${ }^{6}$ Naciones Unidas, World Population Prospects. Key findings \& advance tables, 2017.
} 
cuáles son los principales retos de futuro, así como las posibilidades de reforma del tratado a la luz de nuevos instrumentos internacionales, como la Agenda 2030, o la revisión de algunos ya existentes como es el caso de la Directiva Marco del Agua.

\section{ANTECEDENTES}

\section{Los acuerdos Bilaterales entre España y Portugal}

Las relaciones convencionales hispano-portuguesas destinadas a regular las relaciones transfronterizas en lo relativo a los recursos hídricos se extienden desde el siglo XIX. A lo largo de dicho siglo y durante el siglo XX se sucedieron tratados cuya finalidad y objeto varió a lo largo del tiempo y en función del tratado en cuestión7. Una posible calificación sería aquella que distinguiría entre los tratados destinados a establecer los límites fronterizos ${ }^{8}$, aquellos destinados a regular la navegación y el comercio por los ríos internacionales ${ }^{9} \mathrm{y}$, por último, los

\footnotetext{
7 Para un análisis en profundidad de los antecedentes históricos de las relaciones bilaterales entre España y Portugal con relación a los recursos hídricos compartidos y de los tratados anteriores al Convenio de Albufeira véase Pilar Serrano Pozo, "El régimen jurídico de los cursos de agua hispano-portugueses", en Anuario Español de Derecho Internacional, 15, 1998.

8 Las propias características geográficas de la península ibérica y la utilización de elementos naturales para delimitar los territorios estatales llevaron a que 563 de los 987 kilómetros de frontera tengan carácter fluvial, véase: Adela M. Aura y Larios De Medrano, "La adhesión española a la Convención de Nueva York: consecuencias sobre el vigente régimen de caudales de las aguas de las cuencas hidrográficas hispano lusas", en Sebastián Félix Utrera Caro (Coor.), Agua, Trasvases Y Medio Ambiente: Las Cuencas Fluviales Y El Nuevo Plan Hidrológico Nacional, Editorial Dykinson, S.L., 2013, p. 255. En todo caso, es un aspecto que sigue siendo objeto de negociación y transacción entre ambos Estados, ejemplo de ello es el hecho de que el 13 de agosto de 2018 entrara en vigor el "Tratado entre el Reino de España y la República Portuguesa por el que se establece la línea de cierre de las desembocaduras de los ríos Miño y Guadiana y se delimitan los tramos internacionales de ambos ríos, hecho en Vila Real el 30 de mayo de 2017", BOE no189, 6 de agosto de 2018, p. 78.596-78.597, disponible en internet en: $<$ https://www.boe.es/boe/dias/2018/08/06/pdfs/BOE-A-2018-11228.pdf> [Última consulta: $11 / 06 / 19]$.

Entre estos tratados encontramos:

- Convenio entre sus majestades católica y fidelísima para la libre navegación de los ríos Tajo y Duero, concluido en Lisboa a 30 de agosto de 1829. Disponible en internet en: <https://bibliotecadigital.jcyl.es/es/catalogo_imagenes/grupo.cmd?path=10067686> [Última consulta: $11 / 06 / 19]$.

- Anejo al anterior tratado ratificado en el año 1866. Disponible en internet en: <http://cadcalbufeira.eu/es/convenios/antecedentes/ES1_1_tcm61-424786.pdf> [Última consulta: 11/06/19] Este tratado fue completado con el Anejo de 1866 relativo a los ríos limítrofes y a las obras que se proyecten sobre los tramos fronterizos, en especial sobre el río Miño; y el Acta de 1906 donde se aprueba la línea divisoria entre ambos países desde la desembocadura del río Miño hasta la confluencia del Caya con el Guadiana.

${ }^{9}$ Entre estos tratados encontramos:

- Convenio entre sus majestades católica y fidelísima para la libre navegación de los ríos Tajo y Duero, concluido en Lisboa a 30 de agosto de 1829. Disponible en internet en:
} 
tratados cuyo objeto fue establecer el régimen de gestión y uso de los recursos hídricos compartidos.

Los antecedentes propios del Convenio de Albufeira los encontramos, no obstante, en el Canje de notas relativo al aprovechamiento industrial de las aguas de los ríos limítrofes, de 29 de agosto y 2 de septiembre de $1912^{10}$. Los avances técnicos pronto revelaron las posibilidades industriales y de generación de energía de los recursos hídricos, especialmente aquellos que estaban situados en los saltos transfronterizos. Ya por aquel entonces, empresas privadas y semipúblicas desarrollaron planes para producir energía mediante la construcción de presas ${ }^{11}$, lo que obligó a ambos Estados a derogar la previsión establecida en el Anejo de 1866 que prohibía la construcción de obras en los márgenes de los ríos para evitar causar perjuicios ${ }^{12}$. Sin embargo, tal y como señala Santafé Martínez ${ }^{13}$ :

"Desde el punto de vista de la modernidad en el tratamiento de las cuestiones ligadas al uso compartido de los recursos hídricos parece más lógico detener la mirada en el Convenio de agosto de 1927, ya derogado, para regular el aprovechamiento hidroeléctrico del tramo internacional del río Duero en el que se encuentran elementos clave que van a configurar las relaciones convencionales en esta materia hasta nuestros días".

El Convenio de 1927 sobre el aprovechamiento hidroeléctrico del tramo internacional del río Duero ${ }^{14}$ sentó las bases del esquema de aprovechamiento

<https://bibliotecadigital.jcyl.es/es/catalogo_imagenes/grupo.cmd?path=10067686> [Última consulta: 11/06/19].

- Convenio entre las coronas de España y Portugal para la libre navegación del río Duero, firmado en Lisboa el 31 de agosto de 1835. Contenido en Tratados, convenios y declaraciones de paz y de comercio, Universidad Complutense de Madrid, 1843, p. 869-871. Disponible en internet en: <https://goo.gl/PxWTza> [última consulta: 11/06/19].

10 Disponible en internet en: <http://www.cadc-albufeira.eu/imagenes/es/ES1_4_tcm61424787.pdf> [Última consulta: 11/06/19].

${ }^{11}$ Ana Barreira, "La gestión de las cuencas hispano-portuguesas: El Convenio de Albufeira", en Panel Científico-Técnico de seguimiento de la política de aguas, Fundación Nueva Cultura del Agua, 2008, p. 3.

${ }^{12}$ Así lo establecía el artículo 4. Según establece la profesora Sereno Rosado, tal medida se introdujo para "evitar que las construcciones ribereñas pudieran resultar perjudiciales para cualquiera de los usos que los Estados pudieran plantear". Véase: Amparo Sereno Rosado, Ríos que nos separan, aguas que nos unen: análisis jurídico de los convenios hispano-lusos sobre aguas internacionales, Fundación Lex Nova, Valladolid, 2011, p. 68.

13 José María Santafé Martínez, "El Convenio de Albufeira visión a los diez años", en La política comunitaria de aguas: marco de la acción estatal y autonómica, I Jornadas sobre el agua en España, cuestiones jurídicas y económicas, Adela M. Aura y Larios de Medrano (coord.), 2012, p. 235-270.

${ }_{14}$ Disponible en internet en: <http://cadc-albufeira.eu/es/convenios/antecedentes/ES1_5_tcm61424694.pdf> [Última consulta:11/06/19]. 
que se ha mantenido vigente hasta hoy. Con la finalidad de maximizar el potencial hidroeléctrico de los tramos internacionales se distribuyeron de manera equitativa los tramos internacionales y el potencial de éstos ${ }^{15}$. El Convenio también previó el establecimiento de una Comisión Internacional cuya finalidad era regular el ejercicio de los derechos que a ambos Estado se reconocían y dirimir cualquier tipo de cuestión o controversia, jurídica o técnica, que se originase debido al aprovechamiento de los recursos hídricos ${ }^{16}$. En rasgos generales, el Convenio de 1927 detalla y establece una cooperación institucionalizada cuyo fin no fue otro que garantizar el máximo aprovechamiento posible de los recursos hídricos compartidos para satisfacer las necesidades de producción hidroeléctrica.

Con el paso de los años, y tras la provechosa utilización de los recursos hídricos derivada del tratado de 1927, España y Portugal, conscientes de las nuevas posibilidades industriales y económicas derivadas de la utilización de dichos recursos, concluyeron un nuevo tratado: el Convenio de 1964 para regular el aprovechamiento hidroeléctrico de los tramos internacionales del río Duero y sus afluentes ${ }^{17}$. Este tratado cumplía, prácticamente, con las mismas funciones que el de 1927, sin embargo, se produjo una ampliación del ámbito geográfico de aplicación para incluir a los afluentes del río Duero que, por tanto, quedaron incorporados al potencial hidroeléctrico preexistente.

Entre los aspectos destacables del convenio encontramos la alternancia que pactaron ambos Estados en la situación de Estado aguas arriba y Estado aguas abajo ${ }^{18}$, acuerdo de sumo interés en tanto que impide que cualquiera de ellos adopte una posición preeminente ${ }^{19}$. Por otro lado, la evolución de los intereses estatales tuvo también un claro reflejo tratado al establecer la prevalencia del aprovechamiento hidroeléctrico frente a la navegación en caso de conflicto entre

\footnotetext{
15 Santafé Martínez, "El Convenio del Albufeira...", cit., p. 242.

${ }^{16}$ Esta Comisión que se constituyó tenía, por tanto, una triple función: consultiva, resolutiva e interventora. Así lo establece el artículo 14 del Convenio que también establece la composición; tres vocales designados por cada uno de los Estados y reuniones que se celebrarían de manera alternativa en Madrid y Lisboa.

17 Disponible en internet en: <http://cadc-albufeira.eu/es/convenios/antecedentes/ES1_8_tcm61424710.pdf> [Última consulta: 11/06/2019]. Completado en este caso por el Protocolo Adicional al Convenio de 1964.

${ }^{18}$ Artículo 2 §1.

${ }^{19}$ Esta posición de preeminencia corresponde de forma casi exclusiva, por razones geográficas y orográficas, a España exceptuando un tramo en el río Guadiana, concretamente el que transcurre entre Évora y Pomarão hasta que vuelve a servir de frontera entre ambos Estados.
} 
ambos usos ${ }^{20}$. Desde la óptica de la cooperación institucionalizada cabe señalar que Convenio de 1964 destaca por constituir la "Comisión Internacional hispanoportuguesa para regular el aprovechamiento hidroeléctrico de los tramos internacionales del río Duero y de sus afluentes" ${ }^{21}$ entre cuyas funciones se encontraba fijar una indemnización o compensación en el caso de que España modificara los caudales que debía recibir Portugal, alterando con ello el principio de uso equitativo y razonable de las aguas.

El éxito que demostró el Convenio de 1964 provocó que la regulación se extendiera al resto de los ríos internacionales y sus afluentes. El Convenio de 1968 para regular el aprovechamiento hidráulico de los tramos internacionales de los ríos Miño, Limia, Tajo, Guadiana, Chanza y sus afluentes ${ }^{22}$ es el último tratado bilateral concluido con anterioridad al Convenio de Albufeira. Entre los motivos que provocaron su conclusión se encuentran la voluntad de los Estados de extender la regulación al resto de ríos internacionales, para así obtener beneficios similares a los obtenidos con el río Duero; o la voluntad de Portugal de garantizar la realización y viabilidad del Plan Alqueva ${ }^{23}$ una vez se hiciera efectivo el Plan Badajoz ${ }^{24}$. Por lo demás, en el plano institucional, la Comisión creada en el Convenio de 1964 fue sustituida por la Comisión hispanoportuguesa para regular el uso y aprovechamiento de los ríos internacionales en sus zonas fronterizas ${ }^{25}$.

\section{El contexto internacional}

En el contenido y en la conclusión del Convenio de Albufeira influyeron de manera sustancial diversos instrumentos internacionales que vieron la luz en la década de los noventa. Por un lado, en el seno de las Naciones Unidas se

\footnotetext{
${ }^{20}$ Artículo 6.

${ }^{21}$ Establecida en el artículo 14, tenía una composición paritaria.

22 Disponible en internet en: <http://cadcalbufeira.eu/es/convenios/antecedentes/ES1_10_tcm61-424695.pdf> [Última consulta: 11/06/2019] Completado a su vez por sus Protocolos Adicionales de 1968 y 1976 respectivamente.

23 Javier Estacio Ferro, "Régimen jurídico de los cursos de agua transfronterizos de la península Ibérica", en Anuario de la Facultad de Derecho, Universidad de Extremadura, 32, 2015-2016, p. 20.

${ }^{24}$ Plan hidráulico de presas y embalses diseñados durante la dictadura de Francisco Franco destinado a dotar de mejores recursos de regadíos a la provincia de Badajoz, así como a la elaboración de un plan de industrialización, usando las aguas del río Guadiana.

${ }^{25}$ Así establecida en el artículo 17 del Convenio de 1964.
} 
adoptaron el Convenio sobre la Protección y Utilización de los Cursos de Agua Transfronterizos y de los Lagos Internacionales de 1992, elaborado por la Comisión Económica de las Naciones Unidas para Europa ${ }^{26}$ (Convenio de Helsinki, en adelante), y la Convención de Naciones Unidas sobre el derecho de uso de los cursos de agua con fines diferentes de la navegación de $1997^{27}$, fruto de la labor de la Comisión de Derecho Internacional y con escasa influencia directa en el contenido Convenio de Albufeira.

La adopción de esta última buscó codificar toda una serie de principios que deberían guiar la elaboración de los tratados bilaterales, o multilaterales, para gestionar los recursos hídricos transfronterizos. Así, pese al escaso número de Estados que han ratificado la Convención, España y Portugal entre ellos, estos principios, que ya forman parte del Derecho internacional consuetudinario, han de ser considerados vinculantes para todos los Estados ${ }^{28}$. Todos ellos: utilización y participación equitativas y razonables, obligación de no causar daños sensibles y cooperación están contemplados de manera directa 0 indirecta ${ }^{29}$ en el Convenio de Albufeira ${ }^{30}$. No obstante, no podemos considerar que la generalidad de sus disposiciones determinara el contenido del Convenio de Albufeira.

${ }^{26}$ ECE/MP.WAT/41, entró en vigor de forma general el 6 de octubre de 1996. Disponible en internet en:

$<$ https://www.unece.org/fileadmin/DAM/env/water/publications/WAT_Text/Convention_text_SPA .pdf> [Última consulta: 11/06/2019].

${ }^{27}$ Esta Convención fue adoptada en mayo de 1997 por la Asamblea General -103 votos a favor, 3 en contra y 27 abstenciones-, véase: NU Doc. A/51/PV.99, 1997, p.4. Entró en vigor el 17 de agosto de 2014 tras transcurrir 90 días desde que se depositase el trigésimo quinto instrumento de ratificación, tal y como establece el artículo 36.2 de la propia Convención. Sobre su entrada en vigor y aspectos más relevantes véase: Laura Movilla Pateiro, "La entrada en vigor de la Convención sobre el Derecho de los usos de los cursos de agua internacionales para fines distintos de la navegación", en Revista Española de Derecho Internacional, vol. 66, núm. 2, 2014, p. 312-316.

28 Stephen McCaffrey, "The 1997 U.N. Watercourses Convention: Retrospect and Prospect", en Global Bussiness \& Development Law Journal, vol. 21, 2008, p.170.

${ }^{29}$ Es el caso del principio de la utilización equitativa y razonable, que no se recoge de manera explícita en el Convenio de Albufeira pero que, sin embargo, inspira el texto. Para una mayor profundización en el asunto véase Adela Aura y Larios De Medrano, "La realización del principio de la utilización equitativa y razonable en la práctica fluvial hispano-lusa", en Revista Española de Derecho Internacional, LIX, p. 697-712, 2007. Sobre el principio de uso equitativo y razonable véase: Ibrahim Kaya, Equitable utilization: the law of the non-navigational uses of international watercourses, Ashgate, 2003 y Owen McIntyre "Utilization of shared international freshwater resources - the meaning and role of "equity" in international water law", en Water International, vol. 38, 2, 2013, p. 112-129.

30 La gran diferencia entre ambos instrumentos reside en la primacía de los principios. En caso de colisión entre los principios de utilización y participación equitativas y razonables y la obligación de no causar daños sensibles la Convención hace prevalecer al primero de ellos. Esta postura es mantenida en la doctrina de forma mayoritaria, entre otros, por BOURNE que concluye: "la Convención, por lo tanto, no consagra la noción de que un proyecto que es efectivamente 
Alejándose de las previsiones genéricas anteriormente mencionadas, el Convenio de Helsinki ${ }^{31}$, cuya orientación está especialmente dirigida a garantizar la protección de los ecosistemas dependientes de los recursos hídricos y a evitar, o minimizar, los efectos de la contaminación transfronteriza ${ }^{32}$, tuvo una influencia aún más directa sobre el contenido del Convenio de Albufeira. Además, de especial importancia es el Protocolo sobre el agua y la salud de $1999^{33}$ en tanto que supuso el giro definitivo de la acción regional hacia la protección de los ecosistemas dependientes y de las propias aguas debido a que establece, aunque como principio sin demasiada concreción, la gestión integrada de los recursos hídricos compartidos en el marco de las cuencas hidrográficas internacionales ${ }^{34}$.

Sin embargo, el establecimiento definitivo de las cuencas hidrográficas ${ }^{35}$ como unidades de gestión de los recursos hídricos en Europa fue introducido por la

equitativo y razonable no puede ser implementado si va a causar un daño significativo a otros Estados ribereños; tampoco que un uso que causa un daño significativo es ipso facto inequitativo o irrazonable. El daño sensible está subordinado al uso equitativo" en Charles Bourne, "The Primacy of the Principle of Equitable Utilization in the 1997 Watercourses Convention", en The Canadian Yearbook of International Law, 1997, p. 230. Contrasta con aquellos que, como RieuClarke, sostienen que ningún uso equitativo o razonable puede causar un daño sensible y, por ello, "ningún Estado de un curso de agua tiene permitido usar el curso de agua en su territorio de modo que se cause un daño sensible a otro Estado del curso de agua o al medio ambiente", véase Alistair Rieu-Clarke, "Comentario al artículo 7 de la Convención de Naciones Unidas sobre cursos de agua", disponible en internet en: <http://www.unwatercoursesconvention.org/theconvention/part-ii-general-principles/article-7-obligation-not-to-cause-significant-harm/7-1commentary/> [Última consulta: 11/06/2019].

${ }^{31} \mathrm{Al}$ respecto conviene señalar que tras la Decisión III/3, adoptada por la Reunión de las Partes el 28 de noviembre de 2003, se enmendaron los artículos 25 y 26 del Convenio de modo que, desde su entrada en vigor el 6 de febrero de 2013, todos los Estados Miembros de las Naciones Unidas pueden adherirse al Convenio. Con ello pierde su naturaleza de instrumento regional para convertirse en un instrumento universal.

32 Como elemento destacable encontramos la introducción explícita del principio de desarrollo sostenible en el artículo 2.5.c) cuando establece: "Al tomar las medidas indicadas en los párrafos 1 y 2 del presente artículo, las Partes se regirán por los principios siguientes: los recursos hídricos se gestionarán de modo que las necesidades de la generación actual se atiendan sin poner en peligro la capacidad de las generaciones futuras para satisfacer sus propias necesidades".

${ }^{33}$ Protocolo sobre el agua y la salud al Convenio de 1992 sobre la protección y utilización de los cursos de agua transfronterizos y de los lagos internacionales, disponible en internet en: <https://www.boe.es/diario_boe/txt.php?id=BOE-A-2009-18783> [Última consulta: 11/06/2019]. 34 Véase el artículo 5.j) del Protocolo.

35 Durante la elaboración de la Convención de Naciones Unidas de 1997, gran parte de los Estados aguas arriba rechazaron la utilización del término "cuenca hidrográfica" al considerar que les era perjudicial y porque consideraban que éstas, al referirse a la parte del territorio por donde fluyen los recursos hídricos, formaban parte del territorio del Estado y, por tanto, no debían ser tratadas de forma diferente al resto del territorio, véase: Stephen McCaffrey, The Law of International Watercourses, Oxford University Press, 2002, p. 37. No obstante, el término es el único que se adecua a las exigencias de llevar a cabo una gestión integrada de los recursos hídricos compartidos. Tal y como afirma MALLA: "si un tratado se adhiere al concepto de cuenca hidrográfica internacional, esto indica un paradigma de gestión con el mayor nivel de integración (...). El resto, siguiendo hacia abajo en la escala, son sistema de cursos de agua internacionales, 
Directiva Marco del Agua, del año $2000^{36}$, de la Unión Europea. Si bien es cierto que su entrada en vigor es posterior a la adopción del Convenio de Albufeira, su influencia en el contenido, debido a que los procesos de redacción se llevaron a cabo de manera paralela, es claramente identificable ${ }^{37}$. Por primera vez, desde la Unión Europea se planteaba una regulación holística de los recursos hídricos en la que la protección medioambiental y de los ecosistemas marinos y terrestres dependientes de los recursos se establece como uno de los objetivos principales $^{38}$. Así, la existencia de la Directiva Marco del Agua, tal y como se verá más adelante, permite que la propia Unión Europea controle, aunque de manera indirecta, el cumplimiento del Convenio de Albufeira debido a que el incumplimiento de sus obligaciones también lo es de la Directiva permitiendo, tal y como señala la profesora Torres Cazorla:

"[la] presentación de recursos por incumplimiento y, como correlato de ello, la imposición de multas coercitivas -cuyo montante en ocasiones puede ser bastante elevado- [lo que] constituye un acicate para los Estados, forzándoles a cumplir con las obligaciones contraídas, de manera general, y en lo concerniente al medioambiente y su protección, de forma específica" ${ }^{39}$.

curso de agua internacional compartido, curso de agua transfronterizo, respectivamente". Véase: Malla, "Current State of the Law of International Watercourses: Progress and Paradigm Shifts 1815-2008", en Nordic Journal of International Law, 77, 2008, p. 468.

36 Directiva 2000/60/CE del Parlamento Europeo y del Consejo, de 23 de octubre de 2000, por la que se establece un marco comunitario de actuación en el ámbito de la política de aguas. Disponible en internet en: <https://eur-lex.europa.eu/legalcontent/ES/TXT/?uri=celex:32000L0060 > [Última consulta: 11/06/2019].

37 Para profundizar en la Directiva Marco del Agua, su contenido y los objetivos con los que se identifica el Convenio de Albufeira véase: Sarah Hendry, "The EU Water Framework Directive Challenges, Gaps and Potential for the Future", en Journal for European Environmental \& Planning Law, Vol. 14, Issue 3-4, 2017, p. 249-268; William Howarth, "Going with the Flow: Integrated Water Resources Management, the EU Water Framework Directive and Ecological Flows", en Legal Studies. The Journal of the Society of Legal Scholars, Vol. 38, Issue 2, 2018, p. 298-319; Helmut Bloch, "European Water Policy and the Water Framework Directive: An Overview", en Journal for European Environmental \& Planning Law, Vol. 1, Issue 3, 2004, p. 170 178; María Carmen Tirado Robles, "La directiva marco de aguas y los problemas de su transposición en los estados miembros", en Adela M. Aura y Larios de Medrano (coord.), La política comunitaria de aguas: marco de la acción estatal y autonómica: I Jornadas sobre el agua en España, cuestiones jurídicas y económicas, 2012, p. 93-126.

${ }^{38} \mathrm{El}$ artículo 1.a) establece: "El objeto de la presente Directiva es establecer un marco para la protección de las aguas superficiales continentales, las aguas de transición, las aguas costeras y las aguas subterráneas que: a) prevenga todo deterioro adicional y proteja y mejore el estado de los ecosistemas acuáticos y, con respecto a sus necesidades de agua, de los ecosistemas terrestres y humedales directamente dependientes de los ecosistemas acuáticos".

Para profundizar sobre la regulación anterior a la Directiva Marco del Agua véase: Suzanne Kingston; Veerle Heyvaert; Aleksandra Cavoski, European Environmental Law, Cambridge University Press, 2017, p. 338-342

${ }^{39}$ Maria Isabel Torres Cazorla, "El agua y la seguridad internacional en el ámbito de las relaciones hispano-lusas. Especial atención a las cuencas fluviales transfronterizas y la cooperación 
Por tanto, la regulación internacional que eclosionó a lo largo de los años noventa del siglo pasado produjo una estructura normativa que constituyó el marco perfecto para revisar los acuerdos bilaterales vigentes entre España y Portugal ${ }^{40}$ de modo que se llevara a cabo una regulación integrada de los recursos hídricos con una clara voluntad de garantizar unos caudales mínimos y una protección de los ecosistemas marinos y terrestres dependientes.

\section{EL CONVENIO DE ALBUFEIRA}

\section{El Convenio: naturaleza y estructura}

El 30 de noviembre de 1998, España y Portugal adoptaron el Convenio sobre cooperación para la protección y el aprovechamiento sostenible de las aguas de las cuencas hidrográficas hispano-portuguesas, hecho "ad referéndum" en Albufeira (en adelante, el Convenio o el Convenio de Albufeira) ${ }^{41}$. Con motivo del vigésimo aniversario de su adopción en el pasado año 2018 y de cara al vigésimo aniversario de su entrada en vigor, que tuvo lugar el 17 de enero del año $2000^{42}$, consideramos que es el momento adecuado para analizar su contenido, revisar sus logros y aspectos mejorables, así como plantear recomendaciones para una futura e hipotética modificación del Convenio.

El Convenio de Albufeira tiene naturaleza de tratado marco bilateral ${ }^{43}$ integrado en la estructura normativa internacional, cuyas normas ambos Estados se

\footnotetext{
bilateral entre vecinos" en Badia Martí (Dir.), Agua, recurso natural limitado. Entre el desarrollo sostenible y la seguridad internacional, Marcial Pons, 2018, p. 185-198, p. 196.

40 Hay que aclarar que en la adopción del Convenio fueron clave las medidas expresadas en el Anteproyecto de Ley del Plan Hidrológico Nacional de 1993, que preveía un trasvase desde el río Duero y una nueva regulación del trasvase Tajo-Segura, pusieron en alerta al gobierno luso, que vio peligrar los caudales que recibía hasta entonces pues los Convenios vigentes y existentes en el momento no ofrecían una respuesta adecuada frente a este problema. En la Cumbre Ibérica de 1993 -Cumbre celebrada en Palma de Mallorca entre el 17 y el 18 de diciembre de 1993- se planteó "la conveniencia de celebrar un nuevo acuerdo susceptible de dar respuesta adecuada al doble objetivo central de protección del medio ambiente y de satisfacción de los nuevos usos". La reunión y las bases del acuerdo futuro que se sentaron en aquel momento fueron de gran importancia en tanto que implicaba actualizar un régimen convencional que no estaba adaptado a la normativa internacional y comunitaria y a la ya asentada conciencia medioambiental.

${ }^{41}$ Convenio sobre cooperación para la protección y el aprovechamiento sostenible de las aguas de las cuencas hidrográficas hispano-portuguesas, hecho "ad referendum" en Albufeira el 30 de noviembre de 1998, disponible en internet en: <https://www.boe.es/diario_boe/txt.php?id=BOEA-2000-2882> [Última consulta: 11/06/2019].

42 La entrada en vigor en dicho momento se produjo conforme al requisito establecido en el artículo 35 del Convenio, es decir, el 17 de enero del año 2000 se produjo la última notificación cruzada entre las Partes comunicando el cumplimiento de los respectivos procedimientos internos para la conclusión de convenios internacionales.

${ }^{43}$ Así se establece en el artículo 2.1 cuyo contenido se encuentra en la nota al pie 43.
} 
comprometen a observar en el desarrollo de su cooperación ${ }^{44}$. Su objeto es "definir el marco de cooperación entre las Partes para la protección de las aguas superficiales y subterráneas y de los ecosistemas acuáticos y terrestres directamente dependientes de ellos y para el aprovechamiento sostenible de los recursos hídricos de las cuencas hidrográficas a que se refiere el artículo 3.1”45, es decir, la de los ríos Miño, Limia, Duero, Tajo y Guadiana.

La base, o fundamento, de la cooperación estará determinada por la coordinación de acciones entre ambos Estados con una triple finalidad: promover y garantizar el buen estado de las aguas, superficiales y subterráneas; lograr un aprovechamiento sostenible; y tomar las medidas necesarias para mitigar los efectos de las inundaciones y las situaciones de sequía y escase ${ }^{46}$. Para lograr estos objetivos las partes establecen como mecanismos de cooperación el intercambio de información, las consultas en el seno de los órganos de cooperación y la adopción de todas las medidas necesarias para la aplicación y desarrollo del Convenio ${ }^{47}$. Consideramos que el hecho de canalizar la cooperación a través de las instituciones creadas por el Convenio reporta grandes beneficios debido a la estabilidad y permanencia que se derivan de su propia existencia, así como por la garantía de que se tendrán en cuenta, cuando no se impondrán, los criterios técnicos frente a otro tipo de intereses.

El contenido del Convenio podría ser esquematizado del siguiente modo: primero se establece el contenido sustantivo, que establece las normas que determinarán la cooperación entre las partes, aquellas que establecen las protección y aprovechamiento sostenible de los recursos hídricos y, por último, las situaciones excepcionales. En segundo lugar, se diseña la estructura institucional, compuesta por la Comisión para la Aplicación y Desarrollo del Convenio (en adelante, CADC) y la Conferencia de las Partes (en adelante, $\mathrm{CdP}$ ). Finalmente, se incluyen dos anexos; el primero concerniente al intercambio de información y el segundo al impacto transfronterizo. Además, el Convenio ha contado con dos instrumentos de desarrollo: el Protocolo Adicional al Convenio y el Protocolo de Revisión del Convenio y el Protocolo Adicional, de

\footnotetext{
${ }^{44}$ Artículo 2.2

${ }^{45}$ Artículo 2.1 del Convenio. Las cuencas hidrográficas internacionales a las que se refiere son las ya citadas correspondientes a los ríos Limia, Miño, Duero, Tajo y Guadiana.

${ }^{46}$ Artículo 4.1.

47 Artículo 4.2.
} 
4 de abril de $2008^{48}$, que modificó aspectos concretos del Convenio y del Protocolo Adicional al Convenio y, esencialmente, estableció un nuevo régimen de caudales mínimos ${ }^{49}$.

\section{El marco institucional del Convenio de Albufeira}

El Convenio de Albufeira previó la constitución de dos órganos a través de los cuales canalizar la cooperación entre España y Portugal, la Conferencia de las Partes y la Comisión para la Aplicación y Desarrollo del Convenio. Al fin y al cabo, para cumplir con los ambiciosos objetivos establecidos en el Convenio era necesario que la estructura institucional garantizara que los mecanismos de cooperación fueran efectivos y eficientes. Desde el año 2008 el marco institucional ha sido completado por el Secretariado Técnico Permanente ${ }^{50}$ (en adelante, STP).

En lo que a la naturaleza de los distintos órganos respecta, cabe diferenciar la naturaleza estrictamente política de la CdP frente a la naturaleza técnica de la CADC y el STP. Las funciones de los órganos técnicos son muy similares, estableciéndose, por tanto, la diferencia en el carácter de permanencia del STP que permite llevar a cabo un control continuo sobre las actividades que se desarrollan en el marco del Convenio sin necesidad de que se reúna de manera extraordinaria la CADC.

48 Éste último publicado en BOE núm. 14, de 16 de enero de 2010, páginas 3425 a 3432 , disponible en internet en: <https://www.boe.es/diario_boe/txt.php?id=BOE-A-2010-652> [Última consulta: 11/06/2019]. Entró en vigor en el año 2009.

49 Pese al establecimiento de un régimen de caudales desde el año 1998, y con la finalidad de cumplir con los propios preceptos del propio Convenio, se revisó el Protocolo Adicional para modificar el régimen de caudales existente hasta el momento; dicha modificación se fundamentó en dos razones: poner fin a la situación de provisionalidad establecida originalmente en el Convenio y garantizar un mejor régimen de caudales que fuese establecido por los órganos constituidos por el Convenio y conforme a criterios técnicos. El régimen de caudales provisional y vigente hasta entonces establecía caudales mínimos anuales, siendo insuficiente para satisfacer las necesidades hídricas de Portugal y las propias derivadas de la protección de los ecosistemas pues, si bien se cumplían con los objetivos anuales durante periodos concretos del año, el flujo era completamente insuficiente en periodos concretos como el estival. Tras la revisión se establecieron para cada una de las cuencas regímenes de caudales mínimos trimestrales, semanales y, en el caso del río Guadiana, incluso diarios.

50 La necesidad de constituir un órgano de cooperación que tuviera una permanencia continuada en el tiempo se tomó en el seno de la $X$ reunión de la CADC, pese a que no se incluyera ninguna previsión sobre su creación en el Convenio. Su constitución definitiva tuvo lugar tras la celebración de la II CdP en las que España y Portugal acordaron su creación con una estructura permanente y una ubicación rotatoria por periodos de dos años en cada uno de los países. 
La CdP está compuesta por los representantes que determinen los respectivos gobiernos de España y Portugal y encabezadas por los ministros correspondientes, o las personas en las que éstos deleguen ${ }^{51}$. No hay ninguna periodicidad establecida en el Convenio para las reuniones y hasta el momento se han reunido en tres ocasiones ${ }^{52}$. Es, al fin y al cabo, un órgano de impulsión política que va a transformar en obligaciones las decisiones adoptadas por los órganos de carácter técnico ${ }^{53}$.

Por otro lado, la CADC está compuesta por delegaciones paritarias nombradas por cada una de las partes y se caracteriza por tener la facultad de crear subcomisiones y grupos de trabajo ${ }^{54}$. Las tareas que se le asignan en el Convenio son muy variadas. La Comisión es un órgano que a su vez lleva a cabo las funciones de control y promoción del cumplimiento de las obligaciones contenidas en el Convenio. En cuanto al Secretariado Técnico Permanente es necesario apuntar que tiene unas funciones similares a las de la CADC ${ }^{55}$, aunque, como ya se ha dicho, con una vocación de permanencia que va más allá de reuniones anuales al desarrollar sus funciones de manera continuada a lo largo del tiempo. Entendemos que el nivel de cooperación debida para el cumplimiento de las obligaciones que se derivan del Convenio exigía la creación

\footnotetext{
${ }^{51}$ Así lo establece el artículo 21 del Convenio.

52 La primera reunión tuvo lugar el 27 de julio de 2005, en Lisboa. Las conclusiones están disponibles en internet en: <htp://cadcalbufeira.eu/imagenes/es/1conferenciadelaspartes_tcm61-424840.pdf> [Última consulta: 11/06/2019]. La segunda reunión tuvo lugar el 19 de febrero de 2008, en Madrid. Las conclusiones están disponibles en internet en: <http://cadcalbufeira.eu/imagenes/es/conclusionesdela2conferenciadelconvenio_completo_vf_tcm61424821.pdf> [Última consulta: 11/06/2019]. La tercera reunión tuvo lugar el 20 de julio de 2015, en Porto. Las conclusiones están disponibles en internet en: <http://cadcalbufeira.eu/imagenes/es/20150720_3_conclusiones_conf_partes_hispano_portug_tcm61424831.pdf> [Última consulta: 11/06/2019].

53 Ya sucedió así con la reforma del Protocolo adicional en lo relativo a la modificación del caudal mínimo en tanto que fue un estudio que se encargó a la CADC que, a su vez, remitió a un Grupo de Trabajo y sólo cuando el estudio estuvo terminado las Partes, en el seno de la segunda CdP se llevó a cabo su modificación que se plasmó en el Protocolo de Revisión.

${ }^{54}$ La creación de subcomisiones y grupos de trabajo es algo que se ha llevado a cabo de manera asidua para estudiar cuestiones concretas. Su constitución y disolución ha variado en función de los objetivos establecidos en la Conferencia de las Partes y de las propias necesidades derivadas del cumplimiento del objeto del Convenio.

55 Entre otros aspectos, sus cometidos son: garantizar una plataforma de intercambio de información y de documentación técnica; coordinar y dinamizar los trabajos técnicos; recoger y centralizar la documentación técnica; asegurar la gestión de las interfaces informáticas con el público y con las partes que intervienen en los trabajos técnicos; garantizar una respuesta sistemática de la evolución de los trabajos; apoyar a los grupos de trabajo en el desarrollo de los estudios y en la elaboración de los informes técnicos relacionados; elaboración de los informes hidrometeorológicos y de seguimiento de los trabajos realizados en el seno de la CADC.
} 
de este órgano, pues el intercambio de información y la cooperación requieren de una continuidad que no existía antes del año 2008. Por ello, con su creación se pone fin a una de las principales carencias originarias del Convenio.

Sin duda alguna, el marco institucional establecido en el Convenio tiene numerosos aspectos positivos. El primero y más importante de todos es la institucionalización efectiva de la cooperación interestatal. Sin duda alguna, esto permite dotar de estabilidad y permanencia a la cooperación, aislándola de los vaivenes políticos. Así, también permite que las cuestiones relativas a la gestión sean adoptadas por un órgano técnico que decide conforme a criterios científicos. No obstante, el hecho de que las decisiones finales deban ser aprobadas por el CdP puede suponer una merma del criterio técnico frente a otros criterios distintos de los puramente técnicos y medioambientales, como podrían ser los políticos.

\section{El contenido sustantivo del Convenio de Albufeira}

Como hemos mencionado anteriormente, el contenido sustantivo del Convenio se divide entre aquellos preceptos destinados a establecer las reglas y obligaciones para hacer efectiva la cooperación entre las partes, aquellos que establecen los mecanismos de protección y aprovechamiento sostenible de los recursos hídricos y, por último, las medidas para hacer frente a las situaciones excepcionales.

La obligación de cooperación entre las partes, derivada del principio de cooperación del Derecho internacional del medio ambiente ${ }^{56}$, comprende dentro de sí varias actividades que ambos Estados deben llevar a cabo. La primera derivada de esta obligación es el intercambio de información ${ }^{57}$ de manera regular a través de la CADC y el Secretariado Técnico Permanente, haciendo así efectiva la cooperación institucionalizada. La información a transmitir es la relativa a la gestión de las aguas de las cuencas hidrográficas, las actividades susceptibles de causar impactos transfronterizos en las mismas y la legislación

\footnotetext{
${ }^{56}$ El deber de cooperación es una norma de derecho consuetudinario que ha sido recogida en el principio 19 de la Declaración de Río de Janeiro de 1992 y por la jurisprudencia internacional. Para profundizar en el conocimiento de dicha norma y en otras normas consuetudinarias de Derecho internacional del medio ambiente véase: Jorge E. Viñuales, "La protección ambiental en el Derecho consuetudinario internacional", en Revista Española de Derecho Internacional, vol. 69/2, 2017, p. 71-91, especialmente p. 80-84.

${ }^{57}$ Recogido en el artículo 5.
} 
vigente, así como sus modificaciones. Por otra parte, y de conformidad con el Derecho de la Unión Europea, las Partes tendrán la obligación de poner a disposición de quien presente una solicitud razonable la información requerida sobre las materias que conciernen al Convenio ${ }^{58}$, permitiendo de este modo la participación pública.

Por otra parte, es importante señalar que, como consecuencia de la institucionalización, las Partes deben hacer de la CADC el mecanismo transmisor de la información cuando una parte vaya a realizar un proyecto o actividad que pueda causar un impacto transfronterizo59 o cuando hayan sometido dichos proyectos 0 actividades a una evaluación de impacto transfronterizo ${ }^{60}$. Por lo demás, se establecen mecanismos de cooperación para mejorar los sistemas de comunicación, alerta y emergencia, y la seguridad de las infraestructuras ${ }^{61}$. En definitiva, el Convenio posibilita que exista una comunicación fluida entre ambos Estados de modo que cualquier cuestión técnica que pueda repercutir sobre los recursos hídricos compartidos sea puesta en conocimiento de los órganos del Convenio antes de que se pueda producir cualquier consecuencia negativa sobre los recursos hídricos o los ecosistemas dependientes.

En esta primera parte del Convenio ya es posible observar algo que se repetirá a lo largo del mismo: a la hora de definir los mecanismos de cooperación en ocasiones se opta por la coordinación de actividades y en otras por la realización conjunta62. Este sistema dual no está libre de inconvenientes y ejemplifica cómo España y Portugal, dentro de los modelos de gestión establecidos en la DMA, han optado por la coordinación en la mayoría de las acciones para gestionar de manera sostenible las cuencas hidrográficas internacionales en lugar de por la realización conjunta de éstas. Los problemas que se derivan de esta decisión serán expuestos con mayor detalle en el siguiente epígrafe.

El Convenio de Albufeira, a diferencia de los tratados anteriores y de conformidad con el marco normativo internacional, tiene como uno de sus objetivos

\footnotetext{
58 Artículo 6 del Convenio de Albufeira.

${ }^{59}$ Artículo 8 del Convenio referente a las consultas sobre impactos fronterizos.

60 Antes de su aprobación tal y como exige el artículo 9 del Convenio.

${ }^{61}$ Artículos 11 y 12 respectivamente.

62 Véase, por ejemplo, el artículo 11 que habla de la institución de sistemas "conjuntos o coordinados" o el artículo 12 que, refiriéndose a la seguridad de las infraestructuras establece que: "Las partes desarrollarán conjuntamente programas específicos sobre la seguridad de las infraestructuras hidráulicas...".
} 
principales garantizar la protección medioambiental, tanto de las aguas como de los ecosistemas dependientes. Las previsiones establecidas en el Convenio se refieren principalmente a garantizar el buen estado cualitativo de las aguas, incluyendo con ello medidas de prevención y control de la contaminación, a la gestión de los usos de las aguas y, finalmente a garantizar el buen estado cuantitativo de las aguas mediante el establecimiento de un régimen de caudales.

Para controlar el buen estado cualitativo de las aguas en el Convenio de Albufeira se prevé inventariar, evaluar y clasificar las aguas transfronterizas ${ }^{63}$, así como coordinar los planes de gestión. A este respecto son dos las cuestiones a destacar. La primera de ellas es que la coordinación en la evaluación de las aguas no ha permitido una clasificación correcta. Ambos Estados han establecido sus propios sistemas de calibración, lo que ha dado lugar a disfuncionalidades $^{64}$ que podrían haber sido evitadas mediante la elaboración conjunta de la evaluación. Algo similar sucede con la elaboración de los planes de gestión de las cuencas hidrográficas internacionales. La DMA establece como mecanismo preferente la elaboración de un único plan de cuenca cuando esta sea compartida entre dos o más Estados miembros. No obstante, y a diferencia de lo que ocurre en otras cuencas hidrográficas internacionales sitas en territorio europeo, como es el caso del Danubio65, España y Portugal decidieron que los planes de cuenca fueran elaborados de manera separada, aunque coordinada. Renunciar al modelo de elaboración conjunta supone también renuncia a las ventajas que este ofrece; en palabras de Rodríguez Redondo:

Este modelo, por lo tanto, ayuda a una mayor coordinación, aportando una gestión del recurso hídrico multinivel (con un enfoque tanto bottom-up como top-down). Los beneficios de un plan hidrológico unitario se van a traducir en una mayor efectividad en el cumplimiento de la normativa ambiental aplicable. Estos beneficios van a derivarse del consenso de los Estados

\footnotetext{
${ }^{63}$ Artículo 13.

64 Antonio Jesús Rodríguez Redondo, "Las mejoras en el desarrollo del proceso de intercalibración, en la Directiva Marco del Agua, a través de la gestión de las cuencas internacionales", en Actualidad Jurídica Ambiental, №90, mayo de 2019, especialmente las p. 916.

65 En el caso del Danubio, y a diferencia de lo que sucede con las cuencas hidrográficas internacionales que comparten España y Portugal, sólo existe un único plan de cuenca. Disponible en internet en: <https://www.icpdr.org/flowpaper/app/\#page=1> [Última consulta: 06/06/2019].
} 
Parte sobre aspectos tan relevantes como, entre otros, la monitorización de las masas de agua, los objetivos que se van a establecer y los programas de medidas.

Pese a todo lo anterior, la principal y más interesante novedad del Convenio es que, a diferencia de todos los tratados anteriores, ambos estados establecieron la obligación de garantizar un régimen de caudales mínimos con los que asegurar un flujo cuantitativo mínimo con unos estándares de calidad que permitieran la protección de los ecosistemas ${ }^{66}$. Así, esta obligación de garantizar un caudal mínimo a lo largo de todo el territorio de la cuenca, pese a que parte de la doctrina como AURA Y LARIOS DE MEDRANO ${ }^{67}$ considere que sólo concierne a España, afecta a ambos Estados. Así se evidencia en el Protocolo Adicional donde se exige respetar a ambos Estados los caudales mínimos de agua y para supervisar que se cumple con los flujos mínimos establecidos se establecen diversas estaciones de control que están situadas en los territorios de ambos Estados. Ello nos lleva a concluir que, pese a que España sea el Estado aguas arriba en la práctica totalidad de las situaciones, no existen asimetrías convencionales en lo que a obligaciones respecta entre ambos Estados ${ }^{68}$.

La inclusión de dichas obligaciones sinalagmáticas puede ser entendida de dos maneras distintas. Por un lado, se podríamos considerar que se trata de un mecanismo destinado a evitar que se produzca una diferencia sustancial en la igualdad de obligaciones; de este modo, el Convenio se convertiría en un tratado que contiene obligaciones recíprocas y no sólo de España respecto de Portugal, con lo que facilitaría la posibilidad de adopción del acuerdo. La otra explicación que motivaría su inclusión es, como se ha mencionado, la propia finalidad del tratado. Es decir, se trata de un Convenio que tiene como finalidad establecer un

\footnotetext{
66 Las obligaciones para los Estados en este sentido consisten en: inventariar, evaluar y clasificar las aguas transfronterizas en función de su estado de calidad, usos actuales y potenciales y los intereses desde el punto de vista de conservación de la naturaleza; atribuir cuando proceda un estatuto de protección especial a las aguas -obligación contenida en el artículo 13-, coordinación de los procedimientos para prevenir y controlar la contaminación producida por la emisiones puntuales y difusas; y por último, se reconocen el derecho de aprovechamiento sostenible de los recursos hídricos así como el de aplicar en su territorio las medidas tendentes a prevenir, eliminar, mitigar y controlar los impactos transfronterizos -obligaciones contenidas en los artículos 14 y 15 .

${ }^{67}$ Aura y Larios de Medrano, "La realización del principio..." cit., p.710.

68 El hecho de que no existan asimetrías formales no impide que existan asimetrías materiales derivada de la propia relación Estado aguas arriba y Estado aguas abajo, pues los primeros tienen control directo sobre los recursos hídricos de los que dependen los segundos. Para mayor profundización en este aspecto véase: Marit Brochmann y Nils Petter Gleditsch, "Shared rivers and conflict - A reconsideration", en Political Geography, 31, 2012, p. 519-527.
} 
marco de cooperación para garantizar el desarrollo sostenible de los recursos hídricos y de los ecosistemas que dependen de él. Al obligarse ambos Estados a garantizar un régimen de caudales mínimos incluso en Portugal, que al ser Estado aguas abajo podría destinar dichos recursos a usos consuntivos sin responder ante España, demuestran que ambos Estados se obligan frente a la propia unidad que la cuenca hidrográfica constituye ${ }^{69}$. En nuestra opinión no se puede disociar un motivo de otro, aunque en todo caso tiene un peso preponderante el último. Así, podemos entender que España tiene unas obligaciones respecto del medio ambiente y Portugal; mientras que Portugal tiene obligaciones respecto de la cuenca hidrográfica, y por ende para con el medio ambiente, de cuyo cumplimiento responde ante España.

Por último, el Convenio regula las medidas a adoptar por las partes en caso de que concurran circunstancias excepcionales tales como la contaminación accidental de las cuencas, las avenidas y las situaciones de sequía y escasez. En general, lo que se establece es un sistema de intercambio de información a través de la CADC para prevenir estos episodios o mitigar sus efectos. Dada las circunstancias hídricas recientes del continente europeo ${ }^{70} \mathrm{y}$, particularmente, las de la península ibérica, la regulación de las situaciones de sequía y escasez cobra una importancia fundamental para garantizar el desarrollo sostenible de los recursos hídricos compartidos y de los ecosistemas que de ellos dependen. Es un régimen que combina medidas programáticas y sustantivas en el que la

\footnotetext{
69 Esta situación no hace sino corroborar la teoría de la unidad de cuenca expuesta por Sereno Rosado en Aguas que nos separan..., cit., que, pese a no ser desarrollada en la presente investigación, es plenamente compartida. La consideración de las cuencas como una sola unidad también está presente en el propio Convenio de Albufeira. El artículo 15.2 establece que: "El aprovechamiento de los recursos hídricos de las cuencas hidrográficas hispano-portuguesas a que se refiere el apartado anterior se realizará de acuerdo con la unidad de las mismas, con las excepciones reguladas en el propio Convenio".

70 Tal y como se afirma desde la UE en el documento "Escasez de agua y sequía en la Unión Europea", de agosto del año 2010. Disponible en internet en: $<$ http://ec.europa.eu/environment/pubs/pdf/factsheets/water_scarcity/es.pdf> [Última consulta: $11 / 06 / 2019$, la escasez del agua es un fenómeno creciente y cada vez más frecuente entre los Estados de la UE. España no se encuentra en una situación sencilla en tanto que es el tercer Estado de la UE en el índice de explotación del agua (Índice que indica la proporción que la cantidad extraída cada año representa dentro del total de los recursos de agua dulce disponibles a largo plazo. Es un indicador de la presión o estrés que se ejerce sobre los recursos de agua dulce. Puede consultarse en internet en: <http://ec.europa.eu/environment/pubs/pdf/factsheets/water_scarcity/es.pdf> [Última consulta: 11/06/2019]) lo que le perjudica, en primer lugar, a ella, y consecuentemente a Portugal como Estado aguas abajo.
} 
influencia europea, esencialmente de la DMA, es innegable y la intervención de los Estados a nivel nacional es de suma importancia.

El Convenio de Albufeira recoge en el artículo 19 las obligaciones de España y Portugal con relación a los supuestos de sequía y escasez de recursos, además del ya mencionado régimen de caudales mínimos, con sus excepciones correspondientes, en el Protocolo Adicional. Tres son las obligaciones que establece dicho artículo para los Estados: coordinar sus actuaciones para prevenir y controlar las situaciones de sequía; establecer mecanismos excepcionales para mitigar los efectos de las mismas; y definir la naturaleza de las excepciones al régimen general. El régimen de caudales está recogido, como se ha indicado supra, en el Protocolo Adicional, de modo que se establecen caudales mínimos anuales, trimestrales, semanales, e incluso diarios, a nivel de cuenca hidrográfica y en secciones determinadas donde se encuentran las estaciones de control. Para cada una de las cuencas hidrográficas se prevé la posibilidad de declarar un periodo de excepción en los supuestos de que las precipitaciones de referencia acumuladas desde el inicio del año hidrológico durante el periodo de referencia -sea anual o trimestral- sean inferiores en un porcentaje determinado a la precipitación media acumulada en la cuenca en el mismo periodo inmediatamente anterior.

La declaración de concurrencia de una situación excepcional exime al Estado declarante de su obligación de garantizar los caudales mínimos previstos en el Protocolo Adicional. Tales circunstancias excepcionales sólo han sido invocadas una vez ${ }^{71}$, lo que puede dar derivar en dos conclusiones: verdaderamente sólo en una ocasión las circunstancias climáticas han impedido cumplir con el régimen de caudales; o las Partes son reticentes a declarar dicha situación, incluso cuando son incapaces de garantizar los caudales mínimos acordados debido a las consecuencias de tal declaración. Dado que el incumplimiento en distintas ocasiones de dicho régimen, como se verá más adelante, por parte de España es un hecho, el segundo razonamiento parece imponerse. Tal negativa nos lleva a inducir que la declaración de la concurrencia de una situación excepcional se puede deber, con los graves perjuicios que ello conlleva para el

\footnotetext{
${ }^{71}$ En el año 2005 debido a la incapacidad de España de garantizar durante una semana el caudal
} mínimo establecido para el río Duero. 
medio ambiente, a que ésta tiene consecuencias para el Estado que la aduce. Estas consecuencias se encuentran en el artículo 6.2 $2^{72}$ del Protocolo Adicional, que obliga a realizar una gestión de las aguas que garantice los usos prioritarios de abastecimiento de poblaciones y usos de carácter social, el mantenimiento de los cultivos leñosos y las condiciones ambientales en el río y su estuario. Es decir, se trata de garantizar el derecho al agua, así como evitar costosos daños al medio ambiente ${ }^{73}$.

\section{UN ANÁLISIS DE LA APLICACIÓN Y PROPUESTAS DE REFORMA PARA EL FUTURO}

\section{Los incumplimientos de España}

Cumplidos veinte años desde que se adoptó el Convenio de Albufeira afirmamos sin ningún género de dudas que los resultados derivados de su aplicación son más que satisfactorios. El grado de cumplimiento de sus obligaciones es alto y su aplicación, salvo excepciones, no ha presentado inconvenientes. No obstante, los mencionados incumplimientos, aunque pocos, pueden ser indicadores de problemas a la hora de gestionar de manera sostenible los recursos hídricos. El marco normativo internacional vigente en el momento de adopción del acuerdo ha profundizado en las cuestiones medioambientales, garantizando la protección de las aguas y los ecosistemas. Ello nos lleva a considerar que, si bien el contenido del Convenio resultó innovador y garantizó una protección de los recursos hídricos y de los ecosistemas dependientes no alcanzada hasta entonces por ningún otro acuerdo hispano-luso anterior, las previsiones en él contenidas pueden ser objeto de revisión y mejora a la luz de nuevos

\footnotetext{
72 El artículo 6.2 establece: "De acuerdo con lo previsto en el artículo 19 del Convenio, durante el periodo excepcionado regulado en los artículos anteriores, la gestión de las aguas, se realizará de manera que asegure, incluso en otras cuencas hidrográficas, los usos prioritarios de abastecimiento de poblaciones y usos de carácter social, en particular, el mantenimiento de los cultivos leñosos y las condiciones ambientales en el río y su estuario en la cuenca de origen, teniendo en cuenta las condiciones propias del régimen natural".

${ }^{73}$ La Directiva Marco del Agua también exige una serie de condiciones, concretamente en el artículo 4.6 donde exime de responsabilidad al Estado que observe un deterioro temporal de las masas de agua en cualquiera de sus cuencas si se debe a causas naturales o de fuerza mayor que sean excepcionales o no hayan podido preverse razonablemente, como es el caso de las sequías prolongadas.
} 
instrumentos como la Agenda 2030 y la revisión de la Directiva Marco del Agua, prevista para el presente $2019^{74}$.

Desde que el Convenio de Albufeira entró en vigor no se ha constatado ningún incumplimiento formal por parte de España o Portugal de las obligaciones contenida en él ${ }^{75}$. Esto no implica que nunca se haya producido un incumplimiento de facto pues se han producido hasta cuatro, y todos ellos por parte de España. El primero de ellos se produjo en el año 2002 al no garantizar los caudales mínimos establecidos por el propio Convenio en la cuenca del río Duero. En esa ocasión España "justificó debidamente su incumplimiento y Portugal declaró estar satisfecho con la justificación presentada"76. El segundo incumplimiento se produjo en el año 2005 y, de nuevo, con relación al río Duero, durante un periodo de sequía que afectaba a ambos países ${ }^{77}$; ante el incumplimiento del régimen de caudales durante más de una semana, Portugal exigió a España que declarara la existencia de circunstancias excepcionales 0 que le indemnizara por dicho incumplimiento ${ }^{78}$. Finalmente, ante la presión ejercida por Portugal, aunque no a través de las vías convencionales, España declaró la concurrencia de circunstancias excepcionales y no tuvo que

\footnotetext{
74 La propia Directiva Marco del Agua recoge en el artículo 19.2: "La Comisión revisará la presente Directiva a más tardar diecinueve años después de su entrada en vigor y propondrá cualquier modificación de la misma que resulte necesaria". La entrada en vigor de ésta se produjo el 22 de diciembre del año 2000 con su publicación en el DOUE L 327. Ello implica que durante el presente año la Comisión llevará a cabo la revisión de la Directiva. El proceso comenzó el 17 de septiembre de 2017, cuando se abrió la hoja de ruta para su revisión junto con la Directiva 2006/118/CE relativa a la protección de las aguas subterráneas contra la contaminación y el deterioro, y la Directiva 2007/60/CE del Parlamento Europeo y del Consejo, de 23 de octubre de 2007 , relativa a la evaluación y gestión de los riesgos de inundación. Actualmente, y hasta el 4 de marzo, está abierto el plazo de consulta pública.

${ }^{75}$ Como expresaron la anterior ministra de Agricultura, Pesca, Alimentación y Medio Ambiente, Isabel García Tejerina, y el ministro de Medio Ambiente luso, João Pedro Matos Fernandes, en la rueda de prensa posterior a la vigésima reunión de la CADC, el Convenio estaba siendo cumplido pese a las quejas de numerosas asociaciones ambientalistas que alegaban lo contrario. También se señaló en dicha rueda de prensa que España sólo ha incumplido en una ocasión con el régimen de caudales mínimos, pero fue durante una semana y posteriormente compensó a Portugal por ello.

EFE, "Portugal y España constatan el cumplimiento del Convenio de Albufeira", 28 de noviembre de 2017, Lisboa. Disponible en internet en: <https:/www.efe.com/efe/espana/mundo/portugal-yespana-constatan-el-cumplimiento-del-convenio-de-albufeira/10001-3451631> [Última consulta: 11/06/2019].

${ }^{76}$ Sereno Rosado, Ríos que nos separan... cit., p. 139.

77 Tal circunstancia obligó a las Partes a constituir en el marco de la V CADC un grupo de trabajo de sequía para regular cómo hacer frente a tales situaciones en situaciones futuras.

$78 \mathrm{Tal}$ petición no se llevó a cabo de manera formal, no obstante, algunos medios de comunicación se hicieron eco de la misma, véase: Rafael Méndez, "Portugal reclama a España seis millones de euros por el bajo caudal del Duero", El País, 6 de junio de 2005, disponible en internet en: <https://elpais.com/diario/2005/06/06/espana/1118008830_850215.html> [Última consulta: 11/06/2019].
} 
compensar económicamente a Portugal por el incumplimiento en el régimen de caudales. Este incumplimiento es paradigmático en tanto que revela lo expresado anteriormente: Ios Estados son reticentes a declarar la concurrencia de circunstancias excepcionales, así como a denunciar a través de las vías convencionales establecidas dichas situaciones. El tercer incumplimiento se produjo en el año 2009 en relación con el caudal mínimo establecido en el Protocolo de Revisión para el río Tajo. Sin embargo, al tratarse del primer año de aplicación de los nuevos regímenes de caudales ambos Estados acordaron determinar que era un periodo transicional y no debía imponerse una compensación ${ }^{79}$ por lo que tampoco fue considerado de manera formal como un incumplimiento de las obligaciones.

El incumplimiento más reciente del Convenio data del año 2017 y, aunque tampoco se llegara a denunciar de manera formal el incumplimiento de las obligaciones establecidas en el Convenio de Albufeira, Portugal recurrió a los mecanismos previstos en el Derecho de la Unión Europea para garantizar sus derechos y asegurarse de que España cumplía con sus obligaciones. De este modo, el marco que ofrece la normativa europea, esencialmente la Directiva Marco del Agua, permitió el control indirecto por parte de la Unión.

El problema se originó debido a la decisión unilateral de España de construir un almacén de residuos nucleares en la central de Almaraz sin la correspondiente evaluación previa del impacto ambiental transfronterizo. Esto constituye un incumplimiento del Convenio de Albufeira, pero también de la Directiva Marco del Agua, motivo por el cual Portugal decidió poner el asunto en conocimiento de la Comisión Europea ${ }^{80}$ para iniciar los trámites del recurso por incumplimiento del Derecho de la Unión Europea. El asunto fue archivado por la Comisión antes de la adopción de un dictamen motivado debido al acuerdo ${ }^{81}$ que llegaron el

\footnotetext{
${ }^{79}$ Así se establece en el Acta de la XIII CADC, del año 2010, donde en la página 3 las Partes establecieron: "Se reconoció asimismo que este año debe ser considerado de transición por las ambigüedades que pudieron haber surgido en su interpretación".

80 Portugal recurrió al mecanismo establecido en el artículo 259 TFUE con relación a la Directiva Marco del Agua en lugar de denunciar el incumplimiento de España del Convenio de Albufeira. Se puede entender que tomó esta decisión como medida de presión al involucrar a la Unión Europea y poner así en manos de la Comisión, o del Tribunal de Justicia posteriormente, la posible solución en lugar de recurrir a los mecanismos de arreglo de las controversias contenidos en el Convenio.

81 Acuerdo amistoso a propósito del asunto de Almaraz, disponible en internet en: $<$ http://europa.eu/rapid/press-release_STATEMENT-17-320_es.htm> [Última consulta: 11/06/2019].
} 
presidente Rajoy y el primer ministro Costa a instancias del presidente de la Comisión en la cumbre de Malta de 3 de febrero de 2017. De este modo, se ejemplificó la importante labor que realiza la Unión Europea como ente supranacional en el control y promoción de cumplimiento de la Directiva Marco del Agua y por ende del propio Convenio de Albufeira.

Todos estos incumplimientos y la reticencia de Portugal a denunciarlos formalmente ponen de relieve dos extremos: la dependencia hídrica de Portugal respecto de España, que "no ha hecho valer sus intereses de forma directa y en el momento adecuado, lo que ha permitido a España no sólo mantener sino incluso fortalecer su posición preponderante en la gestión de este recurso" 22 ; y la preferencia de España por anteponer su interés nacional frente al cumplimiento de las obligaciones internacionales, las cuales interpretaba en función de aquél. Como ya se ha expresado anteriormente, el papel que ejerce la Unión Europea como ente supranacional garante del cumplimiento de la Directiva Marco del Agua ${ }^{83}$, y, por ende, e indirectamente, del Convenio, permite reducir y limitar el rol dominante de España en las relaciones bilaterales con Portugal. Lo que sí es pertinente plantear es si dichos comportamientos, es decir, las reticencias de Portugal para ser más contundente a la hora de denunciar los incumplimientos respecto de los instrumentos por los que está vinculada y la anteposición de intereses nacionales diferentes de la protección medioambiental - la sostenibilidad de los recursos hídricos en momentos puntuales pueden acabar suponiendo un óbice para alcanzar una verdadera gestión sostenible de

En dicho acuerdo España se comprometió a compartir toda la información con Portugal en materia medioambiental y de seguridad nuclear; organizar una visita de las autoridades portuguesas a la central para presentarles las medidas tecnológicas y de seguridad; no emitir ni ejecutar la autorización para comenzar las operaciones del almacén de residuos nucleares hasta que las autoridades portuguesas hubieran examinado la información pertinente y la visita se hubiera llevado a cabo. Por su parte, Portugal se comprometió a retirar la denuncia presentada. 82 Marco António Batista Martins y Fernando Miguel Magano Martins, "La dependencia hídrica de Portugal respecto a España: cuestiones de política y seguridad", en Revista Electrónica de Estudios Internacionales, 33, 2017, p. 18.

${ }^{83}$ Esta función de control también se observó cuando Comisión Europea denunció a España ante el Tribunal de Justicia de la Unión Europea por el incumplimiento de la Directiva Marco del Agua, específicamente por no elaborar a tiempo los planes de cuenca, exceptuando los de Cataluña, y por no haber iniciado el procedimiento de información y participación pública salvo en algunas cuencas concretas. Tras certificar que tales extremos eran ciertos el Tribunal de Justicia de la Unión Europea condenó a España por el incumplimiento de sus obligaciones. Sentencia del Tribunal de Justicia (Sala Sexta), de 4 de octubre de 2012, asunto C-403/11, disponible en internet en: <http://eurlex.europa.eu/LexUriServ/LexUriServ.do?uri=CELEX:62011CJ0403:ES:HTML> [Última consulta: 11/06/2019]. 
los recursos hídricos. La respuesta en este sentido debe ser contundente: si realmente ambos Estados están obligados ante la propia unidad del ecosistema que las cuencas hidrográficas constituyen hay que poner fin a ambos comportamientos.

\section{La política hídrica de España: el trasvase Tajo-Segura}

Como hemos mencionado anteriormente, los incumplimientos de España pueden revelar un problema aún mayor. La gestión que se realiza de las cuencas hidrográficas en España es, en algunos casos, ineficiente y pone en riesgo la sostenibilidad de los recursos hídricos. El trasvase Tajo-Segura ${ }^{84}$ (en adelante, TTS) es un ejemplo paradigmático de cuál es la situación hídrica en la península ibérica, cómo se gestionan los recursos hídricos a nivel político-institucional y cuáles son las consecuencias económicas, sociales y medioambientales de decisiones políticas adoptadas sin tener en cuenta la gestión sostenible de los recursos hídricos y los ecosistemas que dependen de ellos.

La cuenca del Segura sufre una escasez grave de recursos hídricos, consecuencia de la aridez que han provocado la escasez de precipitaciones, las altas temperaturas y los frecuentes episodios de sequía que sufre el territorio y que van en aumento con el devenir de los años en el actual contexto climático. EI TTS se justificaba porque estaba llamado a paliar el déficit crónico existente entre la demanda y la disponibilidad de estos recursos en la región. Sin embargo, "en la situación actual de explotación, y con la premisa básica de no incrementar las necesidades agrarias ni las urbano-turísticas, la cuenca del Segura acumula un déficit de agua que puede oscilar de 400 a $700 \mathrm{hm}^{3} / \mathrm{año"}{ }^{\circ 5}$. Esto se debe principalmente a la actividad agrícola, que requiere de cantidades ingentes de agua para el regadío, y al turismo, que se ha visto beneficiado debido,

\footnotetext{
${ }^{84}$ EI TTS se produce desde la cabecera del río Tajo, concretamente desde los embalses de Entrepeñas y Buendía. En un principio, cuando se planteó el TTS, las cantidades de agua cuyo trasvase estaba previsto eran las denominadas como excedentarias y no suponían más de un $40 \%$ por ciento de las aportaciones naturales a ambos embalses. Sin embargo, las aportaciones durante los últimos treinta años se han reducido a la mitad, lo que implica que las cantidades a trasvasar suponen, en algunas ocasiones, hasta el $80 \%$ de las aportaciones. Información disponible en el documento de la Confederación hidrográfica del Tajo, Plan Hidrológico de la parte española de la Demarcación Hidrográfica del Tajo. Memoria, Madrid, 2015, p. 32. Disponible en internet en: <http://www.chtajo.es/LaCuenca/Planes/PlanHidrologico/Planif_20152021/Documents/PlanTajo/PHT2015-DB-Memoria.pdf> [Última consulta: 11/06/2019].

${ }^{85}$ Alfredo Morales Gil, Antonio Manuel Rico Amorós, María Hernández Hernández, "El trasvase Tajo-Segura", en Observatorio Medioambiental, no. 8, mayo 2005, p. 75.
} 
precisamente, a la escasez de lluvias, lo que ha convertido a la región en un buen destino y ha favorecido el desarrollo del sector.

El aumento descontrolado de estos dos sectores de actividad "se sustenta sobre una escasez natural de agua que se contrarresta mediante la construcción de infraestructuras hidráulicas de abastecimiento, hasta llegar, por su buen funcionamiento, a producir un olvido social de las condiciones reales de disponibilidad de agua en la cuenca hidrográfica"86. Se crea, por tanto, un círculo vicioso mediante el cual se sustenta el crecimiento regional de la cuenca receptora gracias a unos recursos hídricos de los que no dispone de manera natural. Esta situación evidencia una falta absoluta de planificación y de actuación conforme a los principios que orientan la gestión sostenible de los recursos hídricos. En primer lugar, porque se priva a la cuenca cedente, la del río Tajo, de unos volúmenes de agua necesarios para la supervivencia de los ecosistemas que de ella dependen y para el cumplimiento de los objetivos establecidos en la Directiva Marco del Agua y el Convenio de Albufeira. En segundo lugar, porque no se ha favorecido una gestión sostenible de los recursos en la cuenca del Segura al haberse creado la ficción de que existían más recursos de los verdaderamente disponibles, provocando con ello el crecimiento insostenible de la agricultura y el turismo. Todo esto provoca la existencia de un déficit estructural que tiene como principal consecuencia que los recursos hídricos en la cuenca del Segura sean siempre insuficientes, además de provocar un estrés hídrico inasumible en el largo plazo para la cuenca cedente.

No obstante, parece que la política de trasvases que se ha llevado a cabo con total normalidad a lo largo de los años pasados va a sufrir una transformación. La ministra de Transición Ecológica, Teresa Ribera, anunció el fin de la normalización de los trasvases ${ }^{87}$ y en el pasado mes de noviembre, a través de una orden ministerial 88 , se limitó la cantidad trasvasada a $7,5 \mathrm{hm}^{3}$, la

\footnotetext{
86 lbid., p. 79.

${ }^{87}$ Entrevista de Manuel Planelles, El País, "Teresa Ribera: "Llevaremos la ley de cambio climático al Congreso antes de fin de año", donde la ministra afirmó: "algo extraordinario, como los trasvases, no se puede convertir en ordinario". Disponible en internet en: <https://elpais.com/economia/2018/06/30/actualidad/1530371534_228548.html> [Última consulta: 11/06/2019].

88 Boletín Oficial del Estado, jueves 29 de noviembre de 2018, Núm. 288, p. 116423-116425. Disponible en internet en: <https://www.boe.es/boe/dias/2018/11/29/pdfs/BOE-A-201816258.pdf> [Última consulta: 11/06/2019].
} 
estrictamente necesaria para satisfacer las necesidades de consumo humano. Pese a que tal decisión haya suscitado las quejas de los habitantes y representantes políticos e institucionales de la cuenca del Segura ${ }^{89}$, entendemos que la nueva orientación de la política de trasvases adoptada por el Gobierno de España es la adecuada y necesaria para asegurar una gestión sostenible de los recursos hídricos. El problema de la escasez en la cuenca del Segura no se soluciona simplemente con el trasvase de recursos hídricos; éste no ha contribuido a mejorar la situación, sino a un crecimiento descontrolado de la actividad agrícola y turística que ha aumentado las necesidades en la cuenca receptora ${ }^{90}$. Como al mismo tiempo los habitantes de la cuenca cedente han visto cómo se reducían las aportaciones naturales a la cabecera, se han agudizado las diferencias regionales. Por ello, es imprescindible adaptar la regulación y las decisiones en materia de política hídrica a las nuevas circunstancias impuestas por el cambio climático y el aumento de las temperaturas. Si se han reducido las aportaciones naturales a la cabeza del río Tajo como consecuencia del descenso de las precipitaicones y las sequías son cada vez más frecuentes, la regulación debe adaptarse para lograr alcanzar, a la luz de los instrumentos internacionales por los que España está vinculada, especialmente el Convenio de Albufeira, una gestión sostenible de los recursos hídricos. La cuenca del Segura sufre una escasez estructural que puede extenderse al resto de las cuencas de la Península si el aumento de las temperaturas se sigue produciendo al ritmo actual y los recursos hídricos son sometidos al estrés continuo por la anteposición de intereses económicos frente a la protección medioambiental.

\footnotetext{
89 En este sentido, el Consejo de Gobierno de la Comunidad Autónoma de Murcia ha interpuesto un recurso contencioso-administrativo contra la orden ministerial. El anuncio de la interposición está disponible en internet en: <https://www.laopiniondemurcia.es/multimedia/videos/comunidad/2018-12-05-159542gobierno-murciano-interpone-recurso-contra-trasvase-cero.html> [Última consulta: 11/06/2019]. 90 Como se indica en Jorge Olcina, David Saurí, Fernando Vera Rebollo, "Turismo, cambio climático y agua: escenarios de adaptación en la costa mediterránea española", en Jorge Olcina Cantos y Antonio M. Rico Amorós (coord.), Libro Jubilar en Homenaje al profesor Antonio Gil Olcina, Homenatges UA, 2014, p. 171-194, p.185, la solución debe pasar por la limitación de la demanda y una adecuada gestión de los recursos hídricos, no por un incremento del suministro. Es interesante también el estudio de Stefan Gössling, Paul Peeters, C. Michael Hall, Jean-Paul Ceron, Ghislain Dubois, La Vergne Lehmann y Daniel Scott, "Tourism and water use: Supply, demand, and security. An international review", en Tourism Management, 33, p. 1-15 en tanto que pone de relieve el peligro de no asegurar el suministro de agua, en cantidad y calidad, debido a los problemas de escasez en destinos turísticos.
} 


\section{Las posibles reformas del Convenio}

En lo referente a los aspectos sustantivos del Convenio, unos de los aspectos que requiere de revisión es la gestión de los periodos de sequía para hacer frente a la crisis climática. Durante el año hidrológico 2016-2017 se sufrieron periodos intermitentes de sequía que, aunque no llegaron a exigir el reconocimiento de la concurrencia de circunstancias excepcionales, sí que produjeron un grave perjuicio para el sector agrícola en España y Portugal ${ }^{91}$. Sólo unas precipitaciones inusuales durante los meses de febrero y marzo evitaron que ambos Estados se enfrentaran de nuevo a una dura sequía. Esto no hace sino poner de relieve que el cambio climático hace más frecuentes e imprevisibles los fenómenos de sequía y que los costes sociales y económicos de las mismas sean muy altos lo que conduce indefectiblemente a la necesidad dar un paso hacia delante en la regulación bilateral, máxime teniendo en cuenta la falta de regulación europea a este respecto ${ }^{92}$.

91 Tanto es así que las delegaciones española y portuguesa presentaron una nota informativa (Nota de las delegaciones española y portuguesa sobre la situación de sequía en Portugal y España 2016/2017, disponible en internet <http://data.consilium.europa.eu/doc/document/ST-10896-2017-INIT/en/pdf> [Última consulta: 11/06/2019]) al Consejo mediante la cual solicitaban permiso para tomar medidas urgentes de carácter económico respecto de los agricultores debido a los daños causados por la sequía. Estas circunstancias no mejoraron al comienzo del año hidrológico 2017-2018 durante el cual, debido a unos meses de octubre y noviembre muy secos, la precipitación acumulada al comienzo de éste fue un 58\% inferior al valor normal (Datos extraídos del "Resumen de la evolución de las precipitaciones en España desde el inicio del año hidrológico 2017-2018" realizado por la Agencia Estatal de Meteorología, disponible en internet en: <https://www.aemet.es/documentos/es/noticias/2018/Precipitaciones_desde_el_inicio_del_a_hi drologico_2017_hasta_14-03-2018.pdf> [Última consulta: 11/06/2019]]).

92 La Unión Europea tiene pendiente la elaboración de normativa relativa a la sequía puesto que los instrumentos existentes en la actualidad, exceptuando las previsiones de la Directiva Marco del Agua, tienen carácter de soft law. En el año 2007 la Comisión elaboró una Comunicación al Parlamento Europeo y al Consejo para afrontar el desafío de la escasez de agua y la sequía en la Unión Europea (Comunicación de la Comisión al Parlamento Europeo y al Consejo: afrontar el desafío de la escasez de agua y la sequía en la Unión Europea -COM 2007414 final-, disponible en internet en: <https://eur-lex.europa.eu/legalcontent/ES/TXT/?uri=celex:52007DC0414> [Última consulta: 11/06/2019]). . Ésta constituye una base de buenas prácticas que deben seguir los EE.MM. entre las que se incluye asignar los recursos hídricos con mayor eficiencia y financiación, aplicar íntegramente la Directiva Marco del Agua, mejorar la gestión del riesgo de sequía o fomentar una cultura de ahorro del agua. Sin embargo, carece de la fuerza necesaria para vincular a los Estados, por lo que su utilidad queda puesta en entredicho. Por su parte, el Consejo elaboró unas conclusiones (Conclusiones del Consejo, Escasez de agua, sequía y adaptación al cambio climático, Doc. 11061/10, 14 de junio de 2010 (11061/10), disponible en internet en: <http://data.consilium.europa.eu/doc/document/ST-13342-2016-INIT/es/pdf> [Última consulta: 11/06/2019]) en las que analizó el vínculo entre la sequía y el cambio climático, para lo que instó a la creación del Observatorio Europeo de la sequía y la adopción de medidas destinadas a minimizar los efectos de las sequías. 
Esta situación ha suscitado la preocupación de ambos Estados, que en la XXa reunión plenaria de la $\mathrm{CADC}^{93}$ coincidieron en la necesidad de tener en cuenta en los trabajos de planificación hidrológica el cambio climático y los efectos que éste tiene sobre los recursos hídricos. Del mismo modo, encomendaron a los Grupos de Trabajo de Información Hidrológica ${ }^{94}$ que impulsen los trabajos de evaluación de las metodologías de cálculo de caudales y de acceso a los datos de caudal y precipitación, en tiempo real. Todas estas son medidas destinadas a anticiparse a las situaciones de sequía, cada vez más frecuentes en las cuencas hidrográficas compartidas.

Como las situaciones de sequía se hacen más frecuentes e imprevisibles, entendemos que el régimen de caudales mínimos establecido en el Protocolo no puede ser tan rígido. Con esto queremos decir que, ante unas condiciones climáticas cambiantes, el régimen no puede permanecer inalterado durante más de diez años, pues la falta de adaptación adecuada para las situaciones de sequía es fácilmente derivable en un problema crónico de escasez. Para que pierda dicha rigidez es necesario que se extraiga el régimen del protocolo, pudiendo una de las soluciones encontrarse en que sea la CADC la que en sus reuniones periódicas establezca regímenes de caudales con una frecuencia de actualización mayor. Como tomar esta decisión supondría una merma en la soberanía de los Estados, que otorgarían una capacidad de decisión a un órgano técnico que les afectaría directamente y por la que se verían vinculados, una propuesta alternativa reside en que o la Conferencia de las Partes se reúna con mayor frecuencia ${ }^{95}$ para revisar el Protocolo conforme a las exigencias climáticas. Sin embargo, he aquí otro de los déficits de la cooperación institucional existente: la frecuencia de las reuniones entre España y Portugal al más alto nivel, es decir, a través de la CdP, es insuficiente. Tres reuniones en veinte años de vigencia no son las suficientes, especialmente en materia medioambiental que exige un alto nivel de seguimiento y actualización de los

\footnotetext{
${ }^{93}$ Celebrada en Oporto, el 27 de noviembre de 2017. Las actas están disponible en internet en: <http://www.cadc-albufeira.eu/imagenes/es/20181025_ActaXXCADC_sin_anejos_tcm61482349.pdf> [Última consulta: 11/06/2019].

94 Junto al Grupo de Trabajo de Planificación Hidrológica ha asumido las funciones del extinto Grupo de Trabajo sobre Régimen de Caudales, Sequías y Situaciones de Emergencia.

95 Hasta la fecha sólo se ha reunido en tres ocasiones.
} 
tratados ante las circunstancias cambiantes del clima y los nuevos conocimientos técnicos y científicos con relación a los ámbitos regulados.

Como se puede observar, en el cumplimiento de los objetivos establecidos en el Convenio de Albufeira se interponen dos elementos que dificultan dicha tarea: el recelo de los Estados por mantener intacta la soberanía estatal y la ausencia de una mejor regulación para gestionar la sequía y la escasez. Pese a todo, no son obstáculos insalvables, al menos siempre y cuando exista voluntad de facilitar una adecuada gestión de los recursos hídricos compartidos. También hay que señalar que la sostenibilidad de los recursos hídricos y su gestión integrada constituyen uno de los objetivos de desarrollo sostenible de la Agenda 2030, concretamente el objetivo 6 "garantizar la disponibilidad y la gestión sostenible del agua y el saneamiento para todos"96. Por tanto, la adopción y adhesión a la Agenda 2030 junto a la revisión de la Directiva Marco del Agua, hacen del contexto actual el momento propicio para plantear la reforma del Convenio de Albufeira.

Esta revisión del contenido no debe afectar, al menos en principio, al contenido sustantivo más allá del régimen dispuesto para hacer frente a las circunstancias excepcionales, pues, en este sentido, el Convenio se presenta como un instrumento aún con plena vigencia y en la línea de la Directiva Marco del Agua en lo referente a la protección medioambiental. Entendemos que las principales modificaciones tienen que plantearse en el ámbito institucional ya que ello permitiría un mejor cumplimiento de las obligaciones por parte de los Estados. Como hemos explicado anteriormente, el órgano técnico diseñado para institucionalizar la cooperación es la Comisión para la Aplicación y Desarrollo del Convenio. Sin embargo, pese a ser un órgano técnico, las decisiones relevantes están supeditadas a decisiones políticas. Es decir, pese a que se constate un incumplimiento en el régimen de caudales la decisión de declarar la concurrencia de circunstancias excepcionales depende del Estado en cuyo territorio se haya incumplido el régimen, que siempre puede supeditar dicha declaración a otros

\footnotetext{
${ }^{96}$ Concretamente el objetivo 6.5 que establece: "de aquí a 2030, implementar la gestión integrada de los recursos hídricos a todos los niveles, incluso mediante la cooperación transfronteriza, según proceda". Más aspectos relevantes a este respecto se pueden encontrar en Laura Movilla Pateiro, "2015: Un año clave a nivel internacional para el desarrollo sostenible, el cambio climático y el agua", en Revista de Derecho, Agua y Sostenibilidad, núm. 0, 2016, p.1-8.
} 
intereses provocando daños irreversibles para las aguas y los ecosistemas dependientes. Pero no es este el único ejemplo, también hay que contar con que tanto España como Portugal han decidido no elaborar los planes de las cuencas hidrográficas internacionales de manera conjunta, como propone la Directiva Marco ${ }^{97}$, sino de manera coordinada lo que sigue permitiendo un margen de maniobra demasiado amplio para los Estados a la hora de adoptar decisiones en lo referente a las cuencas hidrográficas internacionales.

La transformación de la CADC, aunque difícil, no puede ni debe ser descartada. Si se le dotara de personalidad jurídica, convirtiéndola en una organización internacional con competencias y capacidad de adopción de decisiones de manera autónoma sobre las cuencas hidrográficas internacionales, se desterraría el fantasma de la soberanía que planea siempre sobre cualquier cuestión referente a la gestión de los recursos hídricos compartidos entre ambos Estados. Entre sus funciones se podrían encontrar la elaboración de planes para combatir la escasez, la adopción de medidas de carácter técnico, como la declaración de concurrencia de circunstancias excepcionales, y, sobre todo, el control y promoción del cumplimiento por parte de los Estados respecto del Convenio. De este modo, las decisiones técnicas se adoptarían de manera más eficaz y conforme a criterios no políticos.

En todo caso, hay que poner fin a la duplicidad de planes de cuenca debido a que, aunque éstos estén coordinados, son más ineficientes que los planes conjuntos. Tal circunstancia permite que se sigan adoptando medidas insostenibles como el mencionado trasvase Tajo-Segura. Si ambos Estados elaboraran un único plan de cuenca para cada una de las cuencas hidrográficas internacionales se garantizaría el cumplimiento de las obligaciones y objetivos del Convenio y la Directiva Marco del Agua y se pondría fin a la anteposición de los intereses nacionales frente a la gestión sostenible de los recursos hídricos y los ecosistemas dependientes de éstos. La desertificación que planea sobre la Península Ibérica como consecuencia del cambio climático -un estudio reciente detalla que el aumento de las temperaturas puede provocar que en 2090 toda la mitad sur de la Península se convierta en una zona desértica ${ }^{98}$ - obliga a gestionar

\footnotetext{
${ }^{97}$ Artículo 13.2.

98 Joel Guiot y Wolfgang Cramer, "Climate change: The 2015 Paris Agreement thresholds and Mediterranean basin ecosystems", en Science, octubre de 2016, vol. 354, Issue 6311, p. 466-
} 
los recursos hídricos conforme a la oferta existente y no a la demanda; es esta última la que debe amoldarse a los recursos existentes. Una correcta gestión del agua es indispensable para España y Portugal pues "la buena gobernanza de las aguas superficiales y subterráneas puede hacer a los países más resilientes al cambio climático y pueden tener una importancia crítica para la adaptación al cambio climático"99.

\section{CONCLUSIONES}

El Convenio de Albufeira es el tratado bilateral concluido entre España y Portugal que mejor garantiza la protección y la sostenibilidad de los recursos hídricos compartidos y los ecosistemas dependientes, supeditando los usos consuntivos de los Estados a la protección de las cuencas hidrográficas internacionales. La creación de la estructura institucional y obligacional contenida en el Convenio sólo puede confirmar que ambos Estados no sólo están obligados el uno respecto del otro, sino también ante la propia unidad del ecosistema que las cuencas hidrográficas constituyen, lo que hacen del tratado un instrumento internacional de referencia, aunque difícilmente exportable a otros contextos geográficos diferentes de los propios de la Unión Europea, debido a la labor de control sobre el contenido y promoción de cumplimiento que ésta lleva a cabo y resulta, en lo que a la protección medioambiental se refiere, fundamental.

Por otra parte, consideramos que la cooperación institucionalizada que se diseña en el Convenio de Albufeira es muy positiva e influye en el cumplimiento de su contenido. No obstante, consideramos que, pese a la labor que llevan a cabo con una periodicidad adecuada los órganos de carácter técnico, la Conferencia de las Partes, de carácter político y donde verdaderamente se adoptan las decisiones de relevancia, ha desarrollado una actividad escasa. En veinte años desde la adopción del Convenio sólo se han reunido en tres ocasiones, algo a todas luces insuficiente. La adopción de la Agenda 2030 para el desarrollo sostenible y la declaración del Decenio Internacional para la Acción "Agua para el Desarrollo Sostenible" 2018-2028 deberían haber impulsado nuevas

467. Disponible en internet en: <http://science.sciencemag.org/content/354/6311/465/tab-pdf> [Última consulta: 11/06/2019].

99 Francesco Síndico, F., "Transboundary Water Cooperation and the Sustainable Development Goals", en UNESCO-IHP Advocacy Paper, Paris, 2016, p. 16. 
reuniones para que ambos Estados se comprometan, conjuntamente, a cumplir con los objetivos en ella establecidos.

Del mismo modo, entendemos que la regulación relativa a la concurrencia de circunstancias excepcionales, tales como las avenidas y la sequía, pero especialmente ésta última, necesita de mayor concreción y desarrollo. La escasez y la sequía son los principales problemas a los que tendrán que hacer frente ambos Estados, especialmente España, en los próximos años. En todo caso, esta es una carencia normativa de la que también adolece el derecho de la Unión Europea y que requerirá de la adopción de una norma en el seno de la Unión más allá de los instrumentos ahora existentes que carecen de fuerza vinculante. España y Portugal pueden aprovechar la situación actual de revisión de la Directiva para plantear una reforma del Convenio que se adapte, por un lado, a la reforma resultante, y, por otro, que dote de menos rigidez al régimen de caudales mínimos y permita su adaptación a las situaciones cambiantes consecuencia del cambio climático. También es importante que los Estados se comprometan a alejar el elemento de la soberanía de las relaciones bilaterales, pues la protección y sostenibilidad de los recursos hídricos y los ecosistemas dependientes no puede quedar supeditada a intereses puntuales de los Estados. Por ello, la transformación de la Comisión para la Aplicación y Desarrollo del Convenio en una organización internacional podría ser una medida eficaz y sumamente interesante para situar a España y Portugal a la vanguardia internacional en la gestión de los recursos hídricos compartidos y equipararlas así a otras cuencas europeas.

En definitiva, los veinte años de vigencia del Convenio de Albufeira muestran un balance positivo, pese a determinados aspectos siempre mejorables. La capacidad de adaptación a las nuevas circunstancias que se plantearan en los tiempos venideros va a determinar su capacidad para seguir vigente en el futuro. El Convenio de Albufeira recoge las herramientas necesarias para hacer frente a los retos de futuro que se plantean. Simplemente, es necesario reconsiderar ciertos comportamientos y ponderar intereses para garantizar la sostenibilidad de los recursos hídricos. Nuestro futuro y el de la tierra, en el contexto del cambio climático, depende de una gestión sostenible de los recursos hídricos compartidos y para ello hay que ser exhaustivos en el cumplimiento de las obligaciones internacionales. 


\section{BIBLIOGRAFÍA}

Arias Maldonado, Manuel, Antropoceno. La política en la era de la humana, Taurus, 2018.

Aura y Larios de Medrano, "La adhesión española a la Convención de Nueva York: consecuencias sobre el vigente régimen de caudales de las aguas de las cuencas hidrográficas hispano lusas", en Sebastián Félix Utrera Caro (Coor.), Agua, Trasvases Y Medio Ambiente: Las Cuencas Fluviales Y El Nuevo Plan Hidrológico Nacional, Editorial Dykinson, S.L., 2013, p. 255-275.

Aura y Larios de Medrano, A. M. "La realización del principio de la utilización equitativa y razonable en la práctica fluvial hispano-Iusa", en Revista Española de Derecho Internacional, LIX, pp. 697-712, 2007.

Barreira, Ana, "La gestión de las cuencas hispano-portuguesas: El Convenio de Albufeira", en Panel Científico-Técnico de seguimiento de la política de aguas, Fundación Nueva Cultura del Agua, 2008.

Batista Martins, Marco António y Magano Martins, Fernando Miguel, "La dependencia hídrica de Portugal respecto a España: cuestiones de política y seguridad", Revista Electrónica de Estudios Internacionales, 33, 2017.

Bloch, Helmut, "European Water Policy and the Water Framework Directive: An Overview", Journal for European Environmental \& Planning Law, Vol. 1, Issue 3, 2004, p. 170-178.

Bourne, Charles. B., "The Primacy of the Principle of Equitable Utilization in the 1997 Watercourses Convention", The Canadian Yearbook of International Law, 1997, p. 215-232.

Brochmann, Marit; Gleditsch, Nils Petter, "Shared rivers and conflict - A reconsideration", en Political Geography, 31, 2012, pp. 519-527.

Estacio Ferro, Javier, "Régimen jurídico de los cursos de agua transfronterizos de la península Ibérica", en Anuario de la Facultad de Derecho, Universidad de Extremadura, 32, 2015-2016.

Gössling, Stefan; Peeters, Paul; Hall, C. Michael; Ceron, Jean-Paul; Dubois, Ghislain; Lehmann, La Vergne; Scott, Daniel, "Tourism and water use: Supply, demand, and security. An international review", en Tourism Management, 33, p. $1-15$. 
Guiot, Joel; Cramer, Wolfgang, "Climate change: The 2015 Paris Agreement thresholds and Mediterranean basin ecosystems", en Science, octubre de 2016, vol. 354, Issue 6311, pp. 465-468.

Hendry, Sarah, "The EU Water Framework Directive - Challenges, Gaps and Potential for the Future", en Journal for European Environmental \& Planning Law, Vol. 14, Issue 3-4, 2017, p. 249-268.

Howarth, William, "Going with the Flow: Integrated Water Resources Management, the EU Water Framework Directive and Ecological Flows", Legal Studies. The Journal of the Society of Legal Scholars, Vol. 38, Issue 2, 2018, p. 298-319.

Kaya, Ibrahim, Equitable utilization: the law of the non-navigational uses of international watercourses, Ashgate, 2003.

Kingston, Suzanne; Heyvaert, Veerle; Cavoski, Aleksandra, European Environmental Law, Cambridge University Press, 2017, p. 338-342

Koskenniemi, Martti, "Fragmentación del Derecho Internacional: dificultades derivadas de la diversificación y expansión del Derecho Internacional", A/CON.4/L.682, de 13 de abril de 2006

Malla, Katak, "Current State of the Law of International Watercourses: Progress and Paradigm Shifts 1815-2008", en Nordic Journal of International Law, 77, 2008, p. 461-508.

McCaffrey, Stephen C., "The 1997 U.N. Watercourses Convention: Retrospect and Prospect", Global Bussiness \& Development Law Journal, vol. 21, 2008, p.165-173.

McCaffrey, Stephen C., The Law of International Watercourses, Oxford University Press, 2002.

McIntyre, Owen, "Utilization of shared international freshwater resources - the meaning and role of "equity" in international water law", en Water International, vol. 38, 2, 2013, p. 112-129

Morales Gil, Alfredo; Rico Amorós, Antonio Manuel; Hernández Hernández, María; "El trasvase Tajo-Segura", en Observatorio Medioambiental, no. 8, mayo 2005, página 73-110. 
Movilla Pateiro, Laura, "2015: Un año clave a nivel internacional para el desarrollo sostenible, el cambio climático y el agua", en Revista de Derecho, Agua y Sostenibilidad, núm. 0, 2016, p.1-8.

Movilla Pateiro, Laura, "La entrada en vigor de la Convención sobre el Derecho de los usos de los cursos de agua internacionales para fines distintos de la navegación", en Revista Española de Derecho Internacional, vol. 66, núm. 2, 2014, p. 312-316.

Olcina Cantos, Jorge; Saurí, David; Vera-Rebollo, José Fernando, "Turismo, cambio climático y agua: escenarios de adaptación en la costa mediterránea española", en Jorge Olcina Cantos y Antonio M. Rico Amorós (coord.), Libro Jubilar en Homenaje al profesor Antonio Gil Olcina, Homenatges UA, 2014, p. 171-194.

Rieu-Clarke, A., "Comentario al artículo 7 de la Convención de Naciones Unidas sobre cursos de agua"

Rodríguez Redondo, Antonio Jesús, "Las mejoras en el desarrollo del proceso de intercalibración, en la Directiva Marco del Agua, a través de la gestión de las cuencas internacionales", en Actualidad Jurídica Ambiental, no90, mayo de 2019 Santafé Martínez, José María, "El Convenio de Albufeira visión a los diez años", en La política comunitaria de aguas: marco de la acción estatal y autonómica, I Jornadas sobre el agua en España, cuestiones jurídicas y económicas, Adela M. Aura y Larios de Medrano (coord.), 2012, p. 235-270

Sereno Rosado, Amparo, Ríos que nos separan, aguas que nos unen: análisis jurídico de los convenios hispano-lusos sobre aguas internacionales. Fundación Lex Nova, Valladolid, 2011.

Serrano Pozo, Pilar, "El régimen jurídico de los cursos de agua hispanoportugueses", Anuario Español de Derecho Internacional, 15, 1998, p. 325-361. Síndico, Francesco, "Transboundary Water Cooperation and the Sustainable Development Goals”, UNESCO-IHP Advocacy Paper, Paris, 2016, p. 16.

Tirado Robles, María Carmen, "La directiva marco de aguas y los problemas de su transposición en los estados miembros", en Adela M. Aura y Larios de Medrano (coord.), La política comunitaria de aguas: marco de la acción estatal y autonómica: I Jornadas sobre el agua en España, cuestiones jurídicas y económicas, 2012, p. 93-126. 
Torres Cazorla, María Isabel, "El agua y la seguridad internacional en el ámbito de las relaciones hispano-lusas. Especial atención a las cuencas fluviales transfronterizas y la cooperación bilateral entre vecinos" en Agua, recurso natural limitado. Entre el desarrollo sostenible y la seguridad internacional, Ana Badia Martí (Dir.), Marcial Pons, 2018, pp. 185-198.

Viñuales, Jorge E., "La protección ambiental en el Derecho consuetudinario internacional", en Revista Española de Derecho Internacional, vol. 69/2, 2017, p. 71-91 